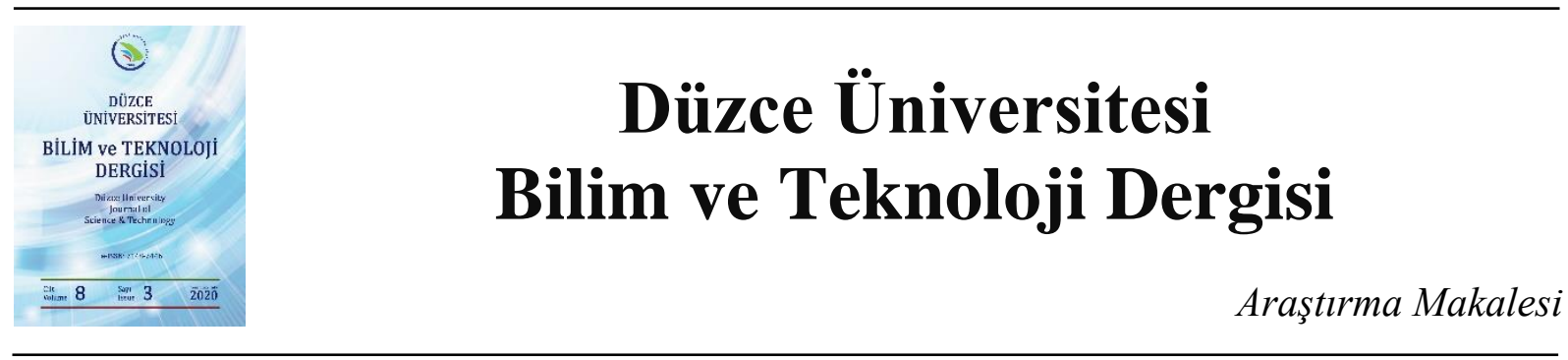

\section{Savunma Sanayindeki Bir İşletmede Tedarik Zinciri Risk Azaltma Stratejilerinin Bulanık DEMATEL Yöntemiyle Analizi}

\author{
Sinan ÇIKMAK ${ }^{\mathrm{a}, *}$, (D) Asuman ÜSTÜNDAĞ ${ }^{\mathrm{b}}$, (D) Mustafa Cahit UNGAN ${ }^{\mathrm{c}}$ \\ ${ }^{a}$ Yönetim ve Organizasyon Bölümü, Sosyal Bilimler MYO, Düzce Üniversitesi, Düzce, TÜRKIYE

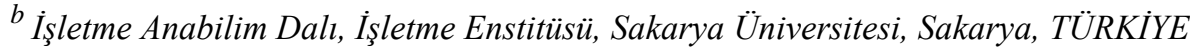 \\ ${ }^{c}$ Işsletme Bölümü, Issletme Fakültesi, Sakarya Üniversitesi, Sakarya, TÜRKIYE \\ * Sorumlu yazarin e-posta adresi: sinancikmak@duzce.edu.tr
}

DOI: 10.29130/dubited.730052

\begin{abstract}
ÖZET
Belirsizliğin yüksek olduğu günümüz iş dünyasında işletmeler tedarik zincirlerindeki riskleri azaltmak için doğru stratejiler kullanmalıdırlar. İşletmelerin kendileri için uygun olan stratejileri seçerken bu stratejilerin birbirlerine olan etkilerini de göz önünde bulundurmaları gerekmektedir. Bu çalışmanın amacı Türk savunma sanayinde en yaygın olarak kullanılan risk azaltma stratejilerini ve bunların arasındaki nedensellik ilişkilerini tespit etmektir. Savunma sanayinde faaliyet gösteren bir işletmeden toplanan veriler bulanık DEMATEL yöntemi kullanılarak analiz edilmiştir. Karşılıklı ilişki ve bağımlılıkların analiz edilmesinde en uygun yöntem olması nedeniyle DEMATEL tercih edilmiştir. Ayrıca uzman yargılarının sayısal değerlere dönüştürülebilmesi amacıyla bulanık teoriden faydalanılmıştır. Elde edilen sonuçlar sırasıyla en önemli risk azaltma stratejilerinin çeviklik, iş birliği, risk paylaşımı, tedarikçi seçme ve geliştirme olduğunu göstermiştir. Diğer stratejileri en fazla etkileyen stratejilerin ise standartlaştırma/ortak parça kullanımı, doğru talep tahmini ve bilgi paylaşımı olduğu görülmektedir. Diğer stratejilerden en fazla etkilenen stratejilerin ise sırasıyla stok bulundurma, çeviklik, risk paylaşımı ve esnek taşımacılık olduğu bulunmuştur. Savunma sanayisinin hassas üretim teknikleri kullanıyor olması, özel kalite standartlarına gereksinim duyması ve çok sayıda alt parçadan oluşan karmaşık ürün yapıları tedarik zincircilerinin risklere karşı hassasiyetini arttırmaktadır. Bu nedenle savunma sanayisindeki işletmelerin uygun risk azaltma stratejilerini belirlemesi önem taşımaktadır. Bu çalışma için yapılan bir literatür taraması savunma sanayi tedarik zincirinde risk azaltma stratejileri ile ilgili bir çalışmanın bulunmadığını göstermiştir. $\mathrm{Bu}$ nedenle bu çalışmanın literatüre önemli bir katkı sağlayacağı düşünülmektedir. Ayrıca, çalışmanın sonuçlarının uygulamacılara daha doğru kararlar vermede yardımcı olacağı umulmaktadır.
\end{abstract}

Anahtar Kelimeler: Bulanık DEMATEL, Risk Azaltma Stratejileri, Tedarik Zinciri Risk Yönetimi

\section{Analysis of Supply Chain Risk Mitigation Strategies in a Defense Industry Company Using Fuzzy DEMATEL Method}

\begin{abstract}
In today's uncertain business environments, companies use various strategies to mitigate risks in their supply chains. To identify the appropriate strategies, businesses need to take interrelationships among the risk mitigation strategies into account. The aim of this study is two-fold. Firstly, it attempts to identify the most commonly used risk mitigation strategies in the Turkish defense industry. Secondly, it purports to explore the causal relationships among the strategies. Data collected from a company operating in the defense industry were analyzed using the fuzzy DEMATEL method. DEMATEL was used in the study since it is the most suitable
\end{abstract}


method for analyzing mutual relationships among supply chain risks. Also, the fuzzy theory was used to transform expert judgments into numerical values. The results showed that the most important risk mitigation strategies are agility, collaboration, risk sharing, supplier selection, and development, respectively. The most influential strategies are found to be standardization/part commonality, accurate demand forecasting, and information sharing. On the other hand, inventory holding, agility, risk-sharing, and flexible transportation are affected the most by the other strategies. The defense industry's sensitive production techniques, strict quality standards, and complex product structures consisting of many subcomponents increase the vulnerability of its supply chains against risks. A literature review for this study showed that there is no study on risk mitigation strategies in the defense supply chain. Therefore, it is considered that this study will make an important contribution to the literature. Also, the findings will guide practitioners to make more sound decisions.

Keywords: Fuzzy DEMATEL, Risk Mitigation Strategies, Supply Chain Risk Management

\section{GIRIS}

Bir işletmenin temel faaliyetlerinin etkinliğini ve verimliliğini olumsuz bir şekilde etkileyebilecek olan riskler tedarik zincirindeki bilgi, malzeme, para ve ürün akışını kesintiye uğratacak olan olaylardır. $\mathrm{Bu}$ riskler, belirsiz müşteri talebi, belirsiz tedarik ve belirsiz maliyetlerle ilgili olabileceği gibi terör saldırıları, ekonomik krizler, devalüasyonlar, grevler, depremler, sel baskınları, kasırgalar vb. doğal afetlerle de alakalı olabilir [1]. Risklere hazırlıksız ve savunmasız bir şekilde yakalanan işletmeler olumsuz sonuçlarla karşı karşıya kalmaktadırlar. Bu sonuçlar arasında satışlarda azalma, maliyet artışı, mali kayıplar, ürün kalitesinin azalması, itibar kaybı ve hatta müşterilerin hayatını tehlikeye sokan durumlar bulunmaktadır [2]. Bu nedenle işletmelerin tedarik zincirlerini tehdit eden çeşitli risklere karşı hazırlıklı olabilmeleri ve bu risklerin olumsuz etkilerini azaltarak faaliyetlerini devam ettirebilmeleri çok önemlidir. İşletmeler, risklerin olumsuz etkilerinden kendilerini korunmak ve tedarik zincirlerlerini daha dirençli hale getirmek için tedarik zinciri risk yönetimi faaliyetlerine yer vermeleri gerekmektedir.

Tedarik zinciri risk yönetimi, sadece odak işletme düzeyinde değil tedarik zincirinin bütününe odaklanarak risklerin tanımlanması ve azaltılmasını amaçlamaktadır [3]. Tedarik zinciri faaliyetlerinin sürekliliğini sağlamak ve risklere karşı kırılganlığı azaltmak amacıyla risk değerlendirme temeline dayalı risk yönetimi için stratejiler uygulanmaktadır [4]. Tedarik zinciri risk yönetim aşamalarının tanımlanmasında farkl11ıklar olmakla birlikte tedarik zinciri risk yönetim süreci genel olarak 4 aşamadan meydana gelmektedir. Bunlar; risk tanımlama, risk değerlendirme, risk azaltma ve risk izlemedir [5]-[7].

Tedarik zinciri risk yönetim aşamalarından biri olan risk azaltma aşamasında, risklerin ortaya çıkma olasılığı veya risklerin olumsuz etkileri azaltılması amaçlanmaktadır [8]. Risk azaltma, çeşitli stratejilerin ve bunlarla ilgili gerekli yatırımların yapılması üzerine çalışmaları ve değerlendirmeleri içermektedir [9]. Risklerin birbirleriyle ilişkili olması, bir tedarik zinciri risk azaltma stratejisinin farklı risk türlerine ve risk azaltma stratejilerine de aynı anda etki etmesine neden olmaktadır. Hatta bazı risk azaltma stratejilerinin belirli risk türlerinin artmasına neden olabildiği görülmüştür [10]. Bu durum uygun stratejilerin seçimini önemli hale getirmekle birlikte doğru stratejilerin seçimini ise oldukça zorlaştırmaktadır.

Askeri araç, gereç, makine, silah, teçhizat ile birlikte askeri ürünlerin üretiminde ihtiyaç duyulan ham madde ve malzemelerin üretimlerinin yapıldığı sanayi koluna savunma sanayisi denilmektedir [11]. Üst düzey teknoloji üretimi ve araştırma geliştirme faaliyetleri nedeniyle savunma sanayisi, endüstrinin en önemli katmanlarından biridir [12]. Dünyadaki askeri ürünlerde yüksek çeşitlilik, teslimat hızı ve uygun operasyonel işlevselliğin olması nedeniyle, savunma sanayi üretim sektörünün önemli bir unsuru olarak kabul edilmektedir [13]. En geniş çerçevede savunma sanayi tedarik zinciri, ham madde üreticisinden başlayarak tüm tedarikçiler ile üreticileri, silahlı kuvvetleri, politikacıları ve halkı kapsamaktadır. Bu nedenle, savunma sanayi tedarik zincirindeki kesintiler ve riskler ülke güvenliği açısından da önemlidir [14]. Savunma sanayi tedarik zincirinde ortaya çıkabilecek risklerden 
bazıları, tedarikçi kaynaklı riskler(malzeme kıtlığı, kalite sorunları ve teslimat gecikmeleri) [15], tek tedarikçiye bağımlılık, uzayan veya aksayan operasyonel süreçler nedeniyle ürün teslimatında gecikme, tedarik zincirinin karmaşıklığ 1 , finansal ve stok yönetimi riskleridir [16]. Sektördeki işletmelerin bu riskleri bertaraf edebilmeleri veya en az zararla atlatabilmeleri için uygun risk azaltma stratejilerini belirlemeleri gerekmektedir.

Çalışma, Türkiye savunma sanayi sektöründe faaliyet gösteren ve çok çeşitli kara savunma araçları üreten bir işletmede gerçekleştirilmiştir. Firma müşterilerinin değişen taleplerinin karşılanmasında özel çözümler geliştirmektedir. Müşterilere sunulan ürünlerde terzi usulü çözümlerin geliştirilmesi parçalarda değişkenliğin artmasına sebep olmaktadır. Bu nedenle tedarikçilerin değişimlere hızlı bir şekilde cevap verebilmesi ve hatasız çalışmaları istenmektedir. Dolayısıyla firmanın ortaya çıkabilecek risklere karşı tedarik zincirinin bütününü kapsayacak strateji uygulamalarını belirlemesi gerekmektedir. Literatürde, savunma sanayisinde uygulanan tedarik zinciri risk azaltma stratejilerinin önem sırasının belirlenmesi ve bu stratejilerin birbirleriyle olan nedensel ilişkilerinin tespit edilmesine yönelik benzer bir çalışmayla karşılaşılmaması çalışmayı orijinal kılmaktadır. Ayrıca, farklı tedarik zincirlerinde tedarik zinciri risk azaltma stratejilerinin ölçümüyle ilgili çalışmaların yetersiz sayıda olması çalışmanın bir diğer motivasyon kaynağıdır [10].

Buradan hareketle çalışma aşağıdaki araştırma sorularına cevap aramaktadır:

(1) Savunma sanayi tedarik zinciri risklerini azaltmada kullanılan stratejiler ve tercih düzeyleri nedir?

(2) Savunma sanayinde tedarik zinciri risk azaltma stratejileri arasında nasıl bir etkileşim vardır?

Çalışmada, savunma sanayisinde faaliyet gösteren bir firmanın, tedarik zinciri risk azaltma stratejilerinin önem sırası belirlenmesi ve bu stratejilerin birbirlerine olan etki düzeyleri tespit etmek amacıyla kriterlerin önem sırasını belirlemek, karşılıklı ilişkileri ve bağımlılıkları analiz etmek için en uygun yöntemlerden biri olan bulanık DEMATEL yöntemi kullanılmıştır.

Çalışmanın bundan sonraki kısımları şu şekilde organize edilmiştir. İkinci bölümde sırasıyla, tedarik zinciri risk azaltma stratejileri ve risk azaltma stratejileri kapsamında yürütülen çalışmaların ele alındığı literatür taraması bulunmaktadır. Üçüncü bölümde, verilerin analizinde kullanılan bulanık DEMATEL metodu anlatılmıştır. Dördüncü bölümde işletmedeki uzmanlardan elde edilen bilgilerin analiz sonuçları tablolar ve grafikler halinde gösterilerek sonuçlar değerlendirilmiştir. Son olarak beşinci bölümde ise çalışmanın sonuçlarına yer verilmiştir.

\section{LITERATÜR İNCELEMESI}

Çalışmanın literatür incelemesi başlığı altında, öncelikle literatürde bulunan tedarik zinciri risk azaltma stratejileriyle ilgili bilgiler verilerek, çalışmanın uygulama kısmında değerlendirilecek olan stratejilerden bahsedilmiştir. Ardından, tedarik zinciri risk azaltma stratejileri konusunda hazırlanmış çalışmalar ve kullandıkları yöntemler incelenmiştir. Son olarak, bulanık DEMATEL metodu anlatılmıştır.

\section{A. TEDARİK ZINCİİ RİSK AZALTMA STRATEJILERİ}

Tedarik zinciri riskini azaltma stratejileri, risklerin ortaya çıkma olasılığını ve olumsuz etkilerini azaltmayı amaçlayan işletme faaliyetlerini ifade etmektedir [17]. Uygun risk azaltma stratejisinin seçiminde işletmeyi tehdit eden risklerin özellikleri ve risk azaltma uygulamaları için tahsis ettiği kaynak miktarı belirleyici olmaktadır [18]. İşletmelerin kendilerine uygun etkin risk azaltma uygulamalarına yer vermeleri başarı sağlamaları için önem taşımaktadır [19]. 
Tedarik zinciri riskini azaltma stratejileri, işletmelerin çeşitli risk kaynaklarından doğan belirsizlikleri azaltmak için bilinçli bir şekilde uyguladığ faaliyetlerdir [2]. Riskleri azaltmak veya risklerin etkilerini hafifletmek için çeşitli risk azaltma stratejileri benimsenebilmektedir [10]. Literatür incelendiğinde çok çeşitli risk azaltma stratejileri ve uygulamalarıyla karşılaşılmaktadır. Jüttner vd. [16] önerdikleri stratejiler, kaçınma, kontrol, işbirliği ve esneklik stratejileridir. Chopra \& Sodhi [19], çalışmalarında; kapasite artırımı, fazladan tedarikçi bulundurma, tepkiselliği artırma, stok artırımı, esnekliğin artırılması, havuz talep oluşturma ve yeteneklerin artırılması stratejilerinden bahsetmişlerdir. Tang [21], tedarik zincirlerini risklere karşı sağlam kılacak dokuz farklı stratejiden bahsetmiştir. Bunlar; erteleme, stratejik stoklama, esnek tedarik temelli yaklaşım, yap veya satın alma yaklaşımı, ekonomik tedarik teşvikleri, esnek taşımacılık, gelir yönetimi, dinamik ürün çeşitlendirme ve sessiz ürün döngüsü olarak ifade edilmiştir. Manuj \& Mentzer [22] risk azaltma stratejilerini; kaçınma, erteleme, spekülasyon, korunma, kontrol, riskin paylaşılması/aktarılması ve güvenlik stratejileri olarak yedi sınıfta toplamışlardır.

Literatüre bakıldığında tedarik zincirlerinin yapısı ve işleyişi gereği çok sayıda riski barındırdığını söylemek mümkündür. Dolayısıyla her bir riskin olası etkilerini azaltabilmek adına işletmeler çeşitli stratejiler geliştirmektedir. Çok sayıda riskten bahsedilebileceği gibi bunlara yönelik sayısız stratejiden de bahsedebiliriz. Fakat yöneticilerin tüm risk ve stratejilere odaklanmaktan ziyade en çok karşılaştıkları risk grubunu düşünerek bunlara uygun stratejiler arasındaki ilişkiyi öncelikle ele almaları daha uygun olacaktır. Bu açıdan bakıldığında tedarik zincirinin temel konularından olan talep, stok yönetimi, tedarikçi ilişkileri, bilgi paylaşımı, esneklik gibi alanlardaki temel risk azaltma stratejilerinin incelenmesi çalışmanın esasını teşkil etmektedir. Literatürde yer alan çok sayıdaki strateji bu çerçevede ve uzman görüşlerinin desteği ile daraltılarak 10 strateji şeklinde çalışmaya konu olmuştur. Aşağıda çalışmanın uygulama kısmında değerlendirilecek olan stratejiler anlatıldıktan sonra Tablo 1'de bu stratejilerin kısa açıklamalarına yer verilmiştir

Talebin doğru tahmin edilmesi, talep riskini azaltmaya yardımc1 olacak bir stratejidir. Arz ve talep uyumsuzluğunun başlıca nedenlerinden birisi de talep tahminlerindeki hatalardır. Doğru talep tahmini yapabilmenin başarısı ise, tedarik zinciri ortakları arasında bilgilerin toplanması ve paylaşılması yeteneğine bağlıdır [23]. Tedarik zincirindeki işletmelerin birbirlerini etkileyebilecek olaylar hakkında doğru ve zamanında bilgi paylaşımında bulunmaları gerekmektedir [24], [25]. Örneğin, tedarikçide meydana gelen olumsuzlukların önceden öğrenilmesi erken uyarı sisteminin devreye sokulmasını sağlayacaktır. Böylece ortaya çıkabilecek bozulmaların önlenmesi mümkün olacaktır.

Tedarik zinciri ortakları ve müşterileri arasında gerçek zamanlı olarak paylaşılan bilgiler, iş operasyonlarındaki hızı, çevikliği, kontrolü ve müşteriye cevap verilebilirliği arttırmaktadır [26]. Tedarik zinciri ortakları arasındaki bilgi paylaşımı, tedarik zincirindeki iç ve dış risklerin azaltılmasındaki kilit faktörlerdendir [6]. Tedarik zinciri risklerinin etkilerini azaltan bir strateji olan bilgi paylaşımı [27], riskli durumların daha erken ve yüksek düzeyde görünür olmasını sağlar [25].

Taşımacılık, müşteriler ve tedarikçiler arasında malzeme ve kaynak akışını sağlayarak, fiziksel bir bağlantı görevi gördüğü için tedarik zincirinde önemli bir işlevdir [28]. Taşımacıllk faaliyetlerinde ortaya çıkacak sorunların üstesinden gelebilmek esnek olmayı gerektirir. Tang [21] esnek taşımacılı̆̆ın üç farklı uygulamayla gerçekleşebileceğini belirtmiştir. İlk uygulama; kara, hava, deniz veya demiryolu taşıma modlarının herhangi birinde ortaya çıkabilecek kesinti durumunda farklı modlarda taşımacılık yapabilme yeteneğine sahip olmaktır [29]. İkincisi, iniş yasakları, işçi grevleri vb. politik aksaklıklar yaşanması durumunda birden fazla taşıma hizmeti sağlayıcısı ile anlaşarak akışın devam etmesini sağlamaktır [21]. Üçüncüsü, mevcut ulaşım rotalarında, gecikmeye veya kesintiye neden olacak bir olay meydana geldiğinde alternatif ulaşım rotalarının kullanılabilmesidir [28].

Stok tutmak arzu edilmeyen bir uygulamadır. Ancak belirli bir seviyede stok bulundurmak, işletmelerin karşılaşacakları risklere karşı hazırlıklı olmalarını sağlamaktadır. Belirsizliklere karşı en yaygın korunma yöntemlerinden biri de kritik parçaların tampon stoklarının oluşturulmasıdır [26]. 
Tedarikçilerden kaynaklanan gecikmelere ve beklenmedik bozulmalara karşı işletmelerde emniyet stokları tutulmaktadır [19].

Tedarik zinciri işbirliği, iki veya daha fazla işletmenin birlikte çalışarak, tek başlarına elde edecekleri karlılık ve rekabet avantajının daha fazlasını elde etmeleridir [31]. İşbirliğine yönelik çabalar arasında, ürün geliştirme ve tam zamanında üretim uygulamalarının koordine edilmesi; talep tahminleri ve teslimat programları hakkında veri alışverişi; maliyet ve diğer stratejik bilgilerin paylaşılması bulunmaktadır [32]. İşbirliği, ortak ürün tasarımı, işbirlikçi araştırma veya kolektif süreç yenilikleriyle tedarik zincirinin çevresel değişikliklere anında yanıt verme yeteneğini artırmaktadır [33]. Dolayısıyla işbirliği, tedarik zinciri risklerini önleyici bir risk azaltma stratejisidir [34].

Yönetilmesi gereken malzeme çeşitliliğinin azalmasını sağlayarak, operasyonel verimliliği arttıran ve ölçek ekonomisi sayesinde maliyetleri düşüren standartlaştırma/ortak parça kullanımı [35] bir risk azaltma stratejisidir [10]. İşletmelerin sundukları ürünlerin çeşitliliğinin artmasıyla birlikte stok riski de artmıştır, tüm ürünlerde ortak bileşenlerin kullanılması bu riski azaltacaktır [19].

İş dünyasındaki belirsizliklerin ve çalkantıların çok fazla olduğu günümüzde işletmelerin rekabetçi kalabilmeleri için tedarik zincirlerinin çevikliği önemli bir yetenek olarak ortaya çıkmıştır [36]. Tedarik zinciri çevikliği , bir tedarik zincirinin hem iç hem de çevresel değişikliklere (fırsat / zorluklar) karşı tetikte olması ve bu değişikliklere zamanında ve esnek bir şekilde yanıt verebilme yeteneğine (proaktif / reaktif yöntemlerle) sahip olmasıdır [37]. Örgütlerin, tedarik zincirlerinde üstün değer sağlamak, bozulma risklerini yönetmek ve müşterilerine kesintisiz hizmet sunmak için çevik olmaları gerekmektedir [38].

Yerel tedarikçilerle çalışılması, değişen pazar koşullarına hızlı ve doğru tepkilerin verilebilmesini, tedarik zincirindeki stok seviyelerinin azaltılmasını ve kar marjının arttırılmasını sağlamaktadır [39]. Talep dalgalanması ne kadar yüksek olursa, yerel tedarikçilerden malzeme satın alma eğilimi o kadar yüksek olmaktadır. Örneğin Benetton, deniz aşırı ülkelerden daha düşük fiyattan malzeme satın almak yerine İtalya'da yerel taşeronları kullanmakta ssrar etmektedir. Çünkü bu firma zamanında teslimat ve trendlere anında yanıt vermeyi daha önemli görmektedir [30].

Risk paylaşımı, riski hafifletmek için riskin bir kısmının tedarik zincirindeki ortaklara aktarılması veya paylaşılmasını içerir. Ürün geliştirme maliyetlerini tedarikçilerle paylaşmak veya sigorta yaptırmak bir risk paylaşım yöntemidir [40]. Ortaklarla risk paylaşımı, tedarik zinciri ağı için önemli faydalar sağlayabilir [41]. Bunlar arasında arz ve talepteki belirsizliklerin, siyasi karışılıkların, döviz kuru dalgalanmalarının ve fiyat dalgalanmalarının olumsuz etkilerini ve maliyetlerini azaltmak sayılabilir [42].

Tedarikçi seçimi, tedarik zinciri yönetimi bağlamında stratejik bir karardır [39]. İşletmelerin zorlu pazar koşullarına karşı tepkisel süreçler geliştirebilmeleri için doğru tedarikçilerle çalışmaları çok önemlidir [30]. Müşteri talebindeki belirsizlikler, yüksek taşımacılık maliyetleri, elektrik kesintileri ve teknik ekipman arızaları gibi operasyonel sorunlar nedeniyle oluşan tedarik belirsizlikleri, doğal felaketler, insan kaynaklı kazalar veya kötü niyetli saldırıları kapsayan risklere karşı dirençli tedarikçilerle çalışmak gerekmektedir [43].

Odak firma ile tedarikçiler arasındaki ilişkilerin geliştirilmesinde uygulanan bilgi paylaşımı ve tedarikçi geliştirme uygulamalarının, aynı zamanda odak işletmenin performansını ve rekabet gücünü artırması beklenir [44]. Günümüzde, işletmelerin müşteri taleplerini yerine getirebilme kabiliyetleri tedarikçilerinin performansına bağımlı hale gelmiştir [45]. Tedarikçilerin geliştirilmesi, fırsatçı davranış riskini ve belirsizlikleri azaltacaktır [44]. 
Tablo 1. Tedarik zinciri risk azaltma stratejileri ve açıklamaları

\begin{tabular}{|c|c|c|c|}
\hline Kod & $\begin{array}{l}\text { Risk Azaltma } \\
\text { Stratejileri }\end{array}$ & Yazarlar & Açıklamalar \\
\hline S1 & $\begin{array}{l}\text { Talep tahmininin } \\
\text { doğru yapılması }\end{array}$ & $\begin{array}{l}\text { Simatupang \& Sridharan } \\
\text { [46], Lee vd. [47] }\end{array}$ & $\begin{array}{l}\text { Arz ve talebin eşleştiği doğru tahmin bilgilerine } \\
\text { erişilmesi }\end{array}$ \\
\hline $\mathbf{S 2}$ & Bilgi paylaşımı & $\begin{array}{l}\text { Kohli \& Jensen [26], Li } \\
\text { vd. [27] }\end{array}$ & $\begin{array}{l}\text { Tedarik zincirindeki firmaların birbirlerini } \\
\text { etkileyebilecek olaylar hakkında zamanında bilgi } \\
\text { alışverişinde bulunmaları }\end{array}$ \\
\hline S3 & Esnek taşımacılık & $\begin{array}{l}\text { Pujawan [29], Tang [21], } \\
\text { Naim vd. [28] }\end{array}$ & $\begin{array}{l}\text { Beklenmedik durumlarda farklı modlarla } \\
\text { taşımacılık yapılması, alternatif ulaşım rotası veya } \\
\text { taşımacılık firması seçilmesi }\end{array}$ \\
\hline S4 & Stok bulundurma & $\begin{array}{l}\text { Chopra \& Sodhi [19], } \\
\text { Kilubi [48] }\end{array}$ & $\begin{array}{l}\text { Çeşitli aksamalara/gecikmelere karşı hazırlıklı } \\
\text { olmak için stok bulundurma }\end{array}$ \\
\hline S5 & $\begin{array}{l}\text { İşbirliğinin } \\
\text { artırılması }\end{array}$ & $\begin{array}{l}\text { Cao vd. [32], Chen vd. } \\
\text { [33], Li vd. [24] }\end{array}$ & $\begin{array}{l}\text { Tedarik zincirindeki firmaların operasyonlarını } \\
\text { geliştirmek için birlikte çalışması, ana işletmenin } \\
\text { tedarik zincirinin diğer üyelerinin gelişmesine } \\
\text { katkı sağlaması, ortak hedeflerin belirlenmesi }\end{array}$ \\
\hline S6 & $\begin{array}{l}\text { Standartlaştırma / } \\
\text { Ortak parça } \\
\text { kullanımı } \\
\end{array}$ & $\begin{array}{l}\text { Baud-Lavigne vd. [35], } \\
\text { (Rajesh vd. [10] }\end{array}$ & $\begin{array}{l}\text { Stok yönetimini kolaylaştıran ve uzmanlaşmayı } \\
\text { artıran standartlaştırma uygulaması, farklı } \\
\text { ürünlerde ortak parça kullanımı }\end{array}$ \\
\hline S7 & $\begin{array}{l}\text { Çevikliğin } \\
\text { arttırılması }\end{array}$ & $\begin{array}{l}\text { Li vd. [37], } \\
\text { Braunscheidel \& Suresh } \\
{[38]}\end{array}$ & $\begin{array}{l}\text { Değişen koşullara hızlı bir şekilde cevap verilmesi, } \\
\text { ortaya çıkan sorunlara hızlı çözümler } \\
\text { geliştirilebilmesi }\end{array}$ \\
\hline S8 & $\begin{array}{l}\text { Yerel } \\
\text { tedarikçilerle } \\
\text { çalışıllması } \\
\end{array}$ & $\begin{array}{l}\text { Bruce vd. [35], } \\
\text { Tachizawa \& Gimenez } \\
{[30]}\end{array}$ & $\begin{array}{l}\text { Maliyet avantajı sağlanması ve çeşitli risk } \\
\text { faktörlerini(taşımadaki gecikmeler, stok fazlalığı) } \\
\text { azaltması nedeniyle yerel tedarikçilerle çalışılması }\end{array}$ \\
\hline S9 & $\begin{array}{l}\text { Risklerin } \\
\text { Paylaşılması }\end{array}$ & $\begin{array}{l}\text { Manuj \& Mentzer [22], } \\
\text { Schlegel \& Trent [40] }\end{array}$ & $\begin{array}{l}\text { Talep risklerinin dağıtıcı ve bayilerle paylaşılması, } \\
\text { tedarikçi kaynaklı risklerin ortaya çıkaracağı } \\
\text { maliyetlerin sözleşmelerle paylaşılması }\end{array}$ \\
\hline S10 & $\begin{array}{l}\text { Tedarikçi seçimi } \\
\text { ve Tedarikçi } \\
\text { geliştirme }\end{array}$ & $\begin{array}{l}\text { Tachizawa \& Gimenez } \\
{[30], \text { Hosseini \& Barker }} \\
{[43]}\end{array}$ & $\begin{array}{l}\text { Doğru tedarikçilerin seçilmesi, tedarikçilerin } \\
\text { denetlenmesi ve iyileştirilmesi }\end{array}$ \\
\hline
\end{tabular}

\section{B. RİSK AZALTMA STRATEJILERİ KAPSAMINDA YÜRÜTÜLEN ÇALIŞMALAR}

$\mathrm{Bu}$ bölümde, tedarik zinciri risk azaltma stratejileri konusunda hazırlanmış çalışmalar ve kullandıkları yöntemler incelenmiştir.

Talluri vd. [49] tedarik zincirindeki risk azaltma stratejilerinin etkinliğini değerlendirdikleri çalışmalarında, risk azaltma stratejilerinin uygunluğunun ve etkinliğinin iç ve dış ortamlara bağlı olduğunu ve herkese uyan tek bir strateji bulunmadığını belirtmişlerdir. Çeşitli risk kategorileri, risk kaynakları ve tedarik zinciri konfigürasyonları varlığında etkin tedarik zinciri risk azaltma stratejilerini değerlendirmek ve önermek için simülasyon metodolojisini, veri zarflama analizini ve parametrik olmayan istatistiksel yöntemi birlikte kullanmışlardır. Çalışmalarında tedarik zinciri aksamalarında yedekleme yerine esneklikle ilgili stratejilerin daha etkin olduğunu tespit etmişlerdir. Liu vd. [50] tarafından yürütülen çalışmada, Çin kimya endüstrisindeki tedarik zinciri risklerini azaltmak ve bütçe hedeflerini aşmadan uygun risk azaltma stratejilerini seçmek için stokastik şans kısıtlı programlama modeli geliştirilmiştir. Geliştirilen modelin test edilmesi sonucunda, en uygun risk azaltma stratejilerinin, kapasite artırımı, esnekliğin arttırılması ve iyi bir planlama olduğu görülmüştür. Sharma \& Bhat [51], risk azaltma stratejilerinin belirlenmesi içi Hindistan otomotiv tedarik zincirindeki 79 otomotiv işletmesinden anket yöntemiyle veri elde etmişlerdir. Bu yazarlar toplanan verilerin analizi sonucunda, kaçınma stratejisinin en çok tercih edilen strateji olduğunu bunu sırasıyla esneklik ve kontrol stratejilerinin takip ettiğini bulmuşlardır. Aqlan \& Lam [52] çalışmalarında, tedarik zinciri risklerini ölçmek ve azaltmak için papyon analizi ve optimizasyon tekniklerine dayanan bir model geliştirmiş̧lerdir. Riskler arasındaki ilişkileri ve bütçe kısıtlamaları altında etki azaltma stratejilerinin 
en iyi kombinasyonunu belirlemeyi amaçlayan bu model, üretim ortamındaki gerçek bir vaka çalışmasıyla test edilmiştir. Çalışmanın bulguları risk azaltma stratejisi seçiminde stratejiyi uygulama maliyetinin belirleyici olduğunu ortaya çıkarmıştır. Ayrıca çalışmada, tüm risklerin tamamen ortadan kaldırılmasının gerekli olmadığı ve işletmelerin her risk için kabul edilebilir bir risk düzeyini belirleyebileceği sonucuna varılmıştır. Bu çalışmanın bir diğer sonucu ise bir risk için uygulanacak bir stratejinin başka bir riski arttıracağ 1 ve risklerin birbirleriyle bağlantılı olduğudur. Rajesh vd. [10] çalışması ise, Hindistan elektronik imalat sektöründeki tedarik zinciri risklerinin belirlenmesi ve bu riskleri azaltacak olan stratejilerin seçilmesini içermektedir. Elektronik imalat tedarik zincirlerine odaklanan 12 ana tedarik zinciri riski ve 21 risk azaltma stratejisi belirlenmiştir. Belirlenen risk azaltma stratejilerinin riskler üzerindeki etkilerine göre sıralamak için gri teori ve graf matrisi yaklaşımları birlikte kullanılmıştır. Yapılan vaka analizinde, kamçı etkisinin azaltılması ve sigorta kullanımı stratejilerinin en etkili risk azaltma stratejileri olduğu ortaya çıkmıştır. Qazi vd. [53], maliyet ve fayda analizi yoluyla farklı risk azaltma stratejilerini değerlendirmek için bir bayes ağ modeli önermişlerdir. Havacılık tedarik zincirinde yapılan bir vaka çalışmasıyla test edilen model, birbiriyle bağlantılı risk tetikleyicileri, risk faktörleri ve risk azaltma stratejilerinin bir ağ ortamında belirli bir bütçe kısıtlaması altında optimal kombinasyonunun belirlenmesini amaçlamaktadır.

Risk azaltma stratejilerinin değerlendirmesi kapsamında, belirli riskleri ve stratejileri değerlendiren çalışmalar da yer almaktadır. Örneğin Ghadge vd. [42] çalışmalarında, küreselleşmiş bir iş ortamında talep belirsizliği ve fiyat oynaklığı risklerini azaltmak için tedarik zinciri risk paylaşım sözleşmesi geliştirilmesi üzerine odaklanmışladır. Geliştirilen tam sayılı programlama modeli ile bir otomotiv işletmesinde test edilerek talep belirsizliği ve fiyat oynaklığ arasında dağıtan bir risk paylaşım sözleşmesi önerilmiştir. Benzer bir şekilde Kull \& Talluri [54], stratejik tedarikçi seçimiyle tedarik risklerini önlemek için AHP(Analitik Hiyerarşi Prosesi) ve amaç programlama yöntemlerini birlikte kullanarak oluşturdukları modeli otomotiv tedarikçisi olan bir imalat işletmesinde test etmiş̧lerdir. Tedarikçi risklerinin azaltılmasına yönelik nükleer enerji güç santrali tedarik zincirinde uygulanan matematiksel bir modelin geliştirildiği çalışmada hata analizi yöntemi kullanılmıştır [55]. Tang \& Tomlin [56], tedarik zinciri risklerini azaltmak için esneklik stratejileri önerirken kısıtlı ve kısitlamasız tam sayılı programlama yöntemiyle 5 farklı model sunmuşlardır. Risklere karşı tedarik zinciri hassasiyetini azaltacak ve tedarik zinciri dirençliliğini arttıracak olan stratejilerin çok amaçlı doğrusal olmayan optimizasyon modeliyle belirlendiği (Chowdhury \& Quaddus [57]'in çalışmasında, Bangladeş hazır giyim sektörüne yönelik en fazla tercih edilen stratejiler tespit edilmiştir. Son olarak Rajesh \& Ravi [23] makalelerinde, gri DEMATEL yöntemini kullanarak elektronik sektöründeki bir firmada risk azaltma uygulamalarının neden/sonuç ilişkisini incelemişlerdir. Diğer risk azaltma uygulamalarını en fazla etkileyen uygulamanın dinamik ürün çeşitlendirme olduğu, ikinci sırada doğru talep tahminin yapılması yer aldığı, üçüncü sırada ise esnek tedarik sözleşmelerinin olduğu görülmüştür.

Tedarik zinciri risk azaltma stratejileri kapsamında yapılan söz konusu çalışmalar incelendiğinde, savunma sanayi sektöründe yürütülen bir çalışmanın olmadığı görülmektedir. Risk azaltma stratejilerinin uygulanmasında sektörlere göre farklılıklar olacağı için savunma sanayi sektöründe yapılacak bir çalışma faydalı olacaktır. Ayrıca, risk azaltma stratejilerinin önem sırasının belirlenmesi ve bu stratejilerin birbirlerine olan etkilerinin değerlendirilmesinde en uygun yöntemlerden biri olan bulanık DEMATEL metodunun kullanıldığı bir çalışmayla karşılaşılmamıştır.

\section{METODOLOJI}

Bu bölümde çalışmanın uygulama kısmında kullanılana bulanık DEMATEL metodu anlatılmıştır. Bu kapsamda, DEMATEL metodunun çıkış noktası ve özelliklerine değinildikten sonra bulanık teoriyle temellendirilen bulanık DEMATEL yönteminin uygulama adımlarından bahsedilmiştir. 


\section{A. BULANIK DEMATEL METODU}

DEMATEL(Decision Making Trial and Evaluation Laboratory) yöntemi ilk olarak, Cenevre Battelle Memorial Enstitüsü Bilim ve İnsani İlişkileri Programı tarafından karmaşık ve iç içe geçmiş problem grubunu araştırmak ve çözmek için kullanılmıştır [58], [59]. Bu yöntem, değerlendirme kriterleri arasındaki önem ve nedensel ilişkilerin değerlendirilmesi konusunda en iyi araçlardan biri olarak kabul edilmektedir [60]. Bu modelleme yaklaşımı, her faktörün diğerine etkisini gösteren bir diagraf ve neden-sonuç diyagramının elde edilmesini sağlamaktadır [60].

Grafik teorisi temelinde oluşturulmuş, görselleştirme yöntemiyle problemlerin analiz edilmesini ve çözülmesini sağlayan [61] DEMATEL yöntemi, nedensel ilişkinin daha iyi anlaşılabilmesi için ilgili faktörleri sebep-sonuç (etkileyen-etkilenen) gruplarına bölerek problemleri planlama ve çözme imkanı sunmaktadır. Burada sebep yani etkileyen olarak adlandırdığımız grup içerisinde yer alan kriterler diğer kriterler üstünde daha çok etkiye sahip olduğu ve dolayısıyla öncelikle ele alınması gerektiği düşünülen kriter grubudur. Sonuç yani etkilenen grupta yer alan kriterler ise diğer kriterler tarafından daha çok etki altında kalması sebebiyle düşük önceliği olduğu farz edilen kriter grubudur [60], [62], [63].

Örneklem büyüklüğünün sınırlandırılmasını ihmal ederek karşılıklı ilişki ve bağımlılıkları analiz etmek için en uygun metodoloji olması nedeniyle çalışmada DEMATEL yöntemi seçilmiş̧ir [64]. Kriterleri birbirlerinden bağımsız bir şekilde değerlendiren AHP (Analytical Hierarchical Process) yöntemiyle karşılaştırıldığında DEMATEL metodunun aynı zamanda faktörler arasındaki bağımlılığı bulmaya çalışan bir yapısal modelleme yöntemi olması onun ayırt edici bir özelliğidir [23]. Benzer bir şekilde ISM (Interpretive Structural Modelling) yöntemi faktörler arası ilişkilere odaklanırken, DEMATEL'in ilişkiler arası ağırlıkların atanmasını sağlayarak etki derecelerinin de hesaplanmasını olanaklı kılması bir diğer üstünlüğüdür [65].

Amaç ve kısıtların tam olarak net olmadığı belirsiz durumlarda karar vermek oldukça güçleşmektedir. Bu belirsizlik altında uzmanların karşılaştıkları problemlerle ilgili çıkarım yapmaları ve sözel ifadeler ile değerlendirmiş oldukları ikili ilişkileri nicel olarak tanımlamaları bulanık mantık ile mümkün olmaktadır [66]. Bu bakımdan gerçek hayatımızda karşılaştığımız problemlere çözüm olarak bulanık yöntemlerden faydalanıldığı görülmektedir. DEMATEL yöntemini bulanık teoriyle birleştirerek kullanmak da mümkündür. Literatürde kriterler arasındaki ilişkinin dilsel olarak ele alınıp sonrasında bu ifadelerin bulanık veya net sayılara dönüştürüldüğü farklı alanlarda yapılmış çalışmalar bulunmaktadır. $\mathrm{Wu} \&$ Lee [59] küresel yöneticilerin yetkinliklerini belirlemede, Chang vd. [67] tedarikçi seçiminde göz önünde bulundurulması gereken kriterlerde, [61] yeşil tedarik zinciri uygulamalarında, Zhou vd. [68] acil durum yönetimi kritik başarı faktörlerinin belirlenmesinde, $\mathrm{Wu}$ [69] başarılı bilgi yönetimi faktörlerinin belirlenmesinde, Altuntas vd. [70] tesis yerleşimi probleminde, Routroy \& Sunil Kumar [71] tedarikçi geliştirme programında, Luthra vd. [72] güneş enerjisi sağlayıcılarının değerlendirilmesinde, Tyagi vd. [73] esnek tedarik zinciri performans ölçüm sistemi unsurlarını incelemede, Özdemir [74] limanlarda meydana gelen iş kazalarının nedenlerini belirlemede, Gopal vd. [75] küresel yazılım geliştirme projelerinde bilgi transferinin etkinliğini belirlemede, Chen-Yi vd. [76] lüks araba seçiminde müşteri tercihi davranış modeli kriterlerini belirlemede, Özdemir \& Tüysüz [77] dengeli puan kartı temelli yükseköğretim kurumlarının değerlendirilmesinde, Mangla vd. [78] lojistik yönetimi uygulamalarının kıyaslamasında bulanık DEMATEL’i kullanmışlardır.

DEMATEL metodu bulanık teoriye temellendiği durumda bulanık DEMATEL yönteminin adımları aşağıda gösterilmiştir [79]:

\section{Adım: Bulanık direk ilişki matrisinin oluşturulması}

Kriterler arasındaki ilişkiler Tablo 2'deki ikili karşılaştırma skalası kullanılarak belirlenir. Burada her bir uzman ya da katılımcının cevapları doğrultusunda matris oluşturulur. $\tilde{z}_{i j}$ Sembolü i faktörünün j 
faktörünü etkileme derecesini göstermektedir. $\tilde{Z}^{k}=\left[\tilde{z}_{i j}^{k}\right]$ Formülünde $\mathrm{k}$ her bir katılımcının numarasını belirtir ve bu sayı $1 \leq \mathrm{k} \leq \mathrm{p}$ olmalıdır, $\tilde{Z}^{1}, \tilde{Z}^{2}, \tilde{Z}^{3} \ldots . . \tilde{Z}^{p}$ katılımcıların cevaplarından oluşan ayrı matrisleri göstermektedir. Birden fazla cevaplayıcının olduğu çalışmalarda direk ilişki matrisinin hesaplanabilmesi için verilen cevaplar üzerinden aritmetik ortalamalar hesaplanarak matris oluşturulur $\left(\tilde{Z}=\left[\tilde{z}_{i j}\right]\right)$.

Tablo 2. Bulanık değerlendirme ölçeği

\begin{tabular}{cc}
\hline Dilsel Değişkenler & Üçgensel Bulanık Sayılar \\
\hline Etkisi yok (EY) & $(0 ; 0 ; 0,25)$ \\
\hline Az etkili (AE) & $(0 ; 0,25 ; 0,50)$ \\
\hline Orta etkili (OE) & $(0,25 ; 0,50 ; 0,75)$ \\
\hline Yüksek etkili (YE) & $(0,50 ; 0,75 ; 1)$ \\
\hline Çok yüksek etkili (ÇYE) & $(0,75 ; 1 ; 1)$ \\
\hline
\end{tabular}

$\tilde{Z}=\frac{\tilde{z}^{1}+\tilde{z}^{2}+\cdots+\tilde{z}^{p}}{p}$

$\tilde{Z}=\left[\begin{array}{cccc}0 & \tilde{z}_{12} & \cdots & \tilde{z}_{1 n} \\ \tilde{z}_{21} & 0 & \cdots & \tilde{z}_{2 n} \\ \vdots & \vdots & \ddots & \vdots \\ \tilde{z}_{n 1} & \tilde{z}_{n 2} & \cdots & 0\end{array}\right]$

\section{Adım: Normalleştirilmiş bulanık direk iliş̧ki matrisinin hesaplanması}

Normalleştirilmiş bulanık direk ilişki matrisinin hesaplanmasında üçgensel sayıların sonuncusu olan ' $u$ ' değerinden faydalanılmaktadır. Eşitlik (3) yardımı ile elde edilen ' $r$ ' değeri 1.adımda oluşturulan bulanık direk ilişki matrisindeki her bir değere bölünmektedir. Elde edilen yeni matris normalleştirilmiş bulanık direk ilişki matrisini vermektedir.

$$
\tilde{X}=\left[\begin{array}{cccc}
\tilde{x}_{11} & \tilde{x}_{12} & \cdots & \tilde{x}_{1 n} \\
\tilde{x}_{21} & \tilde{x}_{22} & \cdots & \tilde{x}_{2 n} \\
\vdots & \vdots & \ddots & \vdots \\
\tilde{x}_{n 1} & \tilde{x}_{n 2} & \cdots & \tilde{x}_{n n}
\end{array}\right] \quad \tilde{x}_{i j}=\frac{\tilde{z}_{i j}}{r}=\left(\frac{\ell_{i j}}{r}, \frac{m_{i j}}{r}, \frac{u_{i j}}{r}\right) \quad r=\max _{1 \leq i \leq n}\left(\sum_{j=1}^{n} u_{i j}\right)
$$

\section{Adım: Bulanık toplam ilişski matrisinin hesaplanması}

İşlem kolaylığı açısından normalleştirilmiş bulanık direk ilişki matrisinde her bir üçgensel sayı grubu ayrı matrislere ayrılır ve eşitlik (5) kullanılarak her bir matris için aynı işlem yapılır ve elde edilen sonuçlar tek matriste birleştirilerek bulanık toplam ilişki matrisi oluşturulmaktadır.

$$
X_{\ell}=\left[\begin{array}{cccc}
0 & \ell_{12}^{\prime} & \cdots & \ell_{1 n}^{\prime} \\
\ell_{21}^{\prime} & 0 & \cdots & \ell_{2 n}^{\prime} \\
\vdots & \vdots & \ddots & \vdots \\
\ell_{n 1}^{\prime} & \ell_{n 2}^{\prime} & \cdots & 0
\end{array}\right] \quad X_{m}=\left[\begin{array}{cccc}
0 & m_{12}^{\prime} & \cdots & m_{1 n}^{\prime} \\
m_{21}^{\prime} & 0 & \cdots & m_{2 n}^{\prime} \\
\vdots & \vdots & \ddots & \vdots \\
m_{n 1}^{\prime} & m_{n 2}^{\prime} & \cdots & 0
\end{array}\right] \quad X_{u}=\left[\begin{array}{cccc}
0 & u_{12}^{\prime} & \cdots & u_{1 n}^{\prime} \\
u_{21}^{\prime} & 0 & \cdots & u_{2 n}^{\prime} \\
\vdots & \vdots & \ddots & \vdots \\
u_{n 1}^{\prime} & u_{n 2}^{\prime} & \cdots & 0
\end{array}\right]
$$




$$
\begin{aligned}
& {\left[\ell_{i j}^{\prime \prime}\right]=X_{\ell} \times\left(I-X_{\ell}\right)^{-1}} \\
& {\left[m_{i j}^{\prime \prime}\right]=X_{m} \times\left(I-X_{m}\right)^{-1}} \\
& {\left[u_{i j}^{\prime \prime}\right]=X_{u} \times\left(I-X_{u}\right)^{-1} \quad \tilde{T}=\left[\begin{array}{cccc}
\tilde{t}_{11} & \tilde{t}_{12} & \cdots & \tilde{t}_{1 n} \\
\tilde{t}_{21} & \tilde{t}_{22} & \cdots & \tilde{t}_{2 n} \\
\vdots & \vdots & \ddots & \vdots \\
\tilde{t}_{n 1} & \tilde{t}_{n 2} & \cdots & \tilde{t}_{n n}
\end{array}\right] \quad \tilde{t}_{i j}=\left(\ell_{i j}^{\prime \prime}, m_{i j}^{\prime \prime}, u_{i j}^{\prime \prime}\right)}
\end{aligned}
$$

\section{Adım: Durulaştırma}

Literatürde farklı durulaştırma metotlarından bahsedilmektedir. Bu çalışmada ise Opricovic ve Tzeng tarafından önerilen CFCS (Converting Data into Crisp Values) durulaştırma yöntemi kullanılmıştır [80]. Böylece etkileyen ve etkilenen kriter gruplarının belirlenmesinde üçgensel bulanık sayılar işlem ve yorumlama kolaylığı açısından daha anlaşılabilir net sayı haline dönüştürülmektedir.

$$
\begin{aligned}
& R=\max _{j} u_{i j}, L=\min _{j} \ell_{i j} \text { ve } \Delta=R-L \\
& x_{\ell j}=\left(\ell_{i j}-L\right) / \Delta \\
& x_{m j}=\left(m_{i j}-L\right) / \Delta \\
& x_{u j}=\left(u_{i j}-L\right) / \Delta \\
& x_{j}^{l s}=x_{m j} /\left(1+x_{m j}-x_{\ell j}\right) \\
& x_{j}^{r s}=x_{u j} /\left(1+x_{u j}-x_{m j}\right) \\
& x_{j}^{c r i s p}=\left[x_{j}^{l s} \times\left(1-x_{j}^{l s}\right)+x_{j}^{r s} \times x_{j}^{r s}\right] /\left[1-x_{j}^{l s}+x_{j}^{r s}\right] \\
& \tilde{f}_{i j}^{c r i s p}=L+x_{j}^{c r i s p} \times \Delta \\
& \tilde{T}^{d e f}=\left[\begin{array}{cccc}
\tilde{t}_{11}{ }^{d e f} & \tilde{t}_{12}{ }^{d e f} & \ldots & \tilde{t}_{1 n}{ }^{d e f} \\
\tilde{t}_{21}{ }^{d e f} & \tilde{t}_{22}{ }^{d e f} & \cdots & \tilde{t}_{2 n}{ }^{d e f} \\
\vdots & \vdots & \ddots & \vdots \\
\tilde{t}_{n 1}{ }^{d e f} & \tilde{t}_{n 2}{ }^{d e f} & \cdots & \tilde{t}_{n n}{ }^{d e f}
\end{array}\right] \quad \tilde{t}_{i j}{ }^{d e f}=\left(\ell_{i j}^{\prime \prime}, m_{i j}^{\prime \prime}, u_{i j}^{\prime \prime}\right)^{d e f}
\end{aligned}
$$

\section{Adım: Etkileyen ve etkilenen kriter gruplarının belirlenmesi}

$\tilde{T}^{\text {def }}$ toplam ilişki matrisinin satır toplamları alınır ve nx1 boyutundaki " $\tilde{D}^{\text {def }}$ " matrisi elde edilir. Toplam ilişki matrisinin sütun toplamları ile oluşan matrisin transpozesi alınarak nx1 boyutundaki “

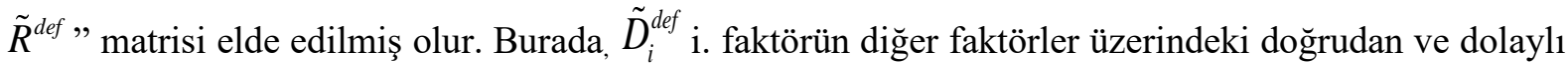
etkilerinin toplamını gösterirken, $\tilde{R}_{i}^{\text {def }}$, diğer kriterlerin i. faktör üzerindeki doğrudan ve dolaylı etkileri toplamını göstermektedir. Daha sonra i. faktörünün sistemin tamamı içerisindeki önem derecesini gösteren $\tilde{D}_{i}^{\text {def }}+\tilde{R}_{i}^{\text {def }}$ ile i. kriterin net etkisini gösteren $\tilde{D}_{i}^{\text {def }}-\tilde{R}_{i}^{\text {def }}$ değerleri belirlenmektedir. $\tilde{D}_{i}^{\text {def }}-\tilde{R}_{i}^{\text {def }}$ sonucunun pozitif değer alması i. kriterin net etkileyen, negatif değer alması ise net etkilenen olduğu anlamına gelmektedir. 
6. Adım: Eşik değerin hesaplanması ve etki-ilişki diyagramının elde edilmesi

$\tilde{T}^{\text {def }}$ Toplam ilişki matrisinde yer alan kriterlerin nispi olarak etkileme derecesi düşük olanları eleyebilmek için bir eşik değer belirlenir. Bu eşik değer çoğu zaman bir uzman tarafından belirlenirken kimi zaman da kartillerden yararlanılarak hesaplanır. Kriterlerin konumun daha net anlaşılabilmesi için de etki-ilişki diyagramında $\tilde{D}_{i}^{\text {def }}+\tilde{R}_{i}^{\text {def }}$ yatay eksende, $\tilde{D}_{i}^{\text {def }}-\tilde{R}_{i}^{\text {def }}$ ise dikey eksende yer alacak şekilde grafik oluşturulur.

\section{SAVUNMA SANAYI İSLETMESINDE VAKA CALISMASI}

İşletmeler bulundukları faaliyet koluna göre bazı riskleri diğer sektörlere göre daha fazla ya da daha az hissedebilirler. Dolayısıyla risklerin etkilerini azaltmaya dönük olan stratejiler bu bağlamda farklılık gösterecektir. Savunma sanayi diğer birçok sektörü etkileyen ve yeni sanayi kollarının gelişimine katkı sağlayan önemli sektörlerden biridir [81]. Üst düzey teknoloji üretimi ve araştırma geliştirme faaliyetleri nedeniyle savunma sanayi üretim endüstrisinin en önemli katmanlarındandır [11]. Bu sebeple çalışma, Türkiye savunma sanayisinde önemli bir yere sahip, çeşitli kara savunma araçları üreten ve Türkiye'nin 500 Büyük Sanayi Kuruluşu içerisinde ilk 200 firma içerisinde yer alan bir firmada vaka çalışması şeklinde gerçekleştirilmiştir. 1000'e yakın çalışanı bulunan firmanın ürettiği zırhlı muharebe araçları dünyanın çeşitli ülkelerine ihraç edilmektedir. Türkiye savunma sanayisi içinde en yüksek yurt dışı satış gelirine sahip üç işletmeden biri olan firmanın çok sayıda tedarikçisi bulunmaktadır. Firma müşterilerin değişen ihtiyaçlarını hızlı bir şekilde karşılayabilmeyi son derece önemli görmektedir. Tedarik zinciri ortakları arasında işbirliklerini güçlendirmeye önem vermektedir. Firma orta/uzun vadede tedarik zincirinin her aşamasında maliyet ve risklerin kontrol edildiği bir yapının kurulmasını istemektedir.

Çalışmanın uygulama aşamasında, öncelikle araştırma konusuyla ilgili sağlıklı bilgilere erişilebileceği düşünülen, işletmenin kalite, üretim planlama ve tedarikçi geliştirme birimlerinde çalş̧an ve 5 ila 15 yıl arasında değişen aralıklarda sektör deneyimleri bulunan 7 uzmanla iletişime geçilmiştir. Uzmanlardan literatür taraması neticesinde elde edilen risk azaltma stratejilerinin işletmeye uygunluğu konusunda değerlendirme yapmaları istenmiştir. Önerilen 10 adet stratejinin işletmeye uygunluğu konusunda görüş birliği sağlanmıştır. Ardından uzmanlardan kendi işletmeleriyle ilgili tedarik zinciri risk azaltma stratejileri arasındaki ikili ilişkileri karşılaştırmaları istenmiştir. Sınırlı sayıda stratejinin uzman değerlendirilmesine sunulmasındaki amaç karmaşıklığı önlemek ve katılımcılardan güvenilir bilgilerin elde edilmek istenmesidir. Çalışmada, stratejilerle ilgili ikili karşılaştırma verilerinin elde edilmesiyle başlayan bulanık DEMATEL uygulama adımları aşağıdaki şekilde gerçekleştirilmiştir.

\section{Adım: Bulanık direk ilişki matrisinin oluşturulması}

$\mathrm{Bu}$ aşamada uzmanlar ikili karşılaştırmaları yaparlarken Tablo 2'deki dilsel ifadeleri kullanmışlardır. Örneğin; 1. uzman, talep tahmininin doğru yapılması stratejisinin (S1), bilgi paylaşımı stratejisi (S2) üzerindeki etkisini 'az etkili (AE)', 2. uzman, 'az etkili (AE)', 3. uzman, 'etkisi yok (EY)', 4. uzman, 'orta etkili (OE)', 5. uzman, 'yüksek etkili (YE)', 6. uzman, 'az etkili (AE)', 7. uzman ise yine 'etkisi yok (EY)' ş̧eklinde cevaplandırmıştır. Her bir strateji ikilisi arasındaki ilişkinin tüm uzmanlar tarafından bu şekilde cevaplandırılması istenmiştir. Tablo 3'te birinci uzman tarafından stratejiler arasında yapılan ikili dilsel karşılaştırma örnek olarak verilmiştir.

Tablo 3. Birinci uzmanın dilsel değerlendirmesi

\begin{tabular}{ccccccccccc}
\hline & S1 & S2 & S3 & S4 & S5 & S6 & S7 & S8 & S9 & S10 \\
\hline S1 & - & AE & YE & YE & OE & AE & AE & EY & EY & EY \\
S2 & ÇYE & - & EY & OE & CYE & OE & OE & EY & OE & AE \\
S3 & EY & EY & - & YE & EY & EY & CYY & EY & YE & EY \\
S4 & EY & EY & EY & - & EY & EY & ÇYE & EY & OE & EY \\
S5 & YE & YE & OE & EY & - & AE & YE & OE & CYY & EY \\
S6 & EY & EY & EY & ÇY & AE & - & CYYE & EY & AE & EY \\
\hline
\end{tabular}


Tablo 3 (devam). Birinci uzmanın dilsel değerlendirmesi

\begin{tabular}{ccccccccccc}
\hline S7 & EY & EY & OE & EY & OE & EY & - & AE & OE & ÇYE \\
\hline S8 & EY & OE & OE & EY & OE & EY & YE & - & EY & OE \\
S9 & EY & ÇYE & EY & EY & YE & EY & ÇYE & EY & - & OE \\
S10 & EY & OE & OE & EY & ÇYE & EY & OE & OE & OE & - \\
\hline
\end{tabular}

Her bir uzmandan elde edilen dilsel ifadeler daha sonra bu ifadelere karşılık gelen bulanık üçgensel sayılara çevrilmiştir. Örneğin Tablo 3'te belirtilen birinci uzmanın dilsel ifadeleri Tablo 4'te görülen üçgensel sayılara dönüştürülmüştür. Tüm uzmanlardan elde edilen görüşler bu şekilde sayısallaştırılmış ve yedi uzman görüşünün aritmetik ortalaması alınarak Tablo 5'teki bulanık direk ilişki matrisi elde edilmiştir.

\section{Adım: Normalleștirilmis bulanık direk ilişki matrisinin elde edilmesi}

$\mathrm{Bu}$ adımda bulanık direk ilişki matrisinde yer alan üçgensel sayılardan ' $u$ ' değerleri satır boyunca toplanmış ve toplam en büyük ' $u$ ' değeri seçilmiştir. Bulanık direk ilişki matrisi içerisinde yer alan her bir değer bu elde edilen ' $u$ ' değerine bölünerek Tablo 6' daki bulanık normalize edilmiş direk ilişki matrisi oluşturmuştur.

\section{Adım: Bulanık toplam ilişki matrisinin elde edilmesi}

Tablo 6'daki normalize edilmiş direk ilişki matrisinde yer alan $\ell, m$ ve $u$ üçgensel sayıları (5) formülleri kullanılarak ayrı birer matris halinde ele alınıp, birim matristen çıkarılmış ve tersi alınmıştır. Elde edilen sonuç yine matrisin kendisiyle çarpılarak Tablo 7'deki bulanık toplam ilişki matrisi elde edilmiştir.

\section{Adım: Durulaştırma işleminin yapılması}

$\mathrm{Bu}$ adımda durulaştırma yöntemi olarak Opricovic ve Tzeng tarafından önerilen CFCS (Converting Data into Crisp Values) tercih edilmiştir. (6), (7), (8), (9), (10), (11), (12), (13) ve (14) formülleri uygulanarak üçgensel sayıların daha anlaşılabilir net sayılara dönüştürülmesi ile Tablo 8 durulaştırılmış bulanık toplam ilişki matrisi oluşturulmuştur. 
Tablo 4. Dilsel değişkenlere karşıllı gelen üçgensel bulanık sayılar

\begin{tabular}{|c|c|c|c|c|c|c|c|c|c|c|c|c|c|c|c|c|c|c|c|c|c|c|c|c|c|c|c|c|c|c|}
\hline & & S1 & & & S2 & & & S3 & & & S4 & & & S5 & & & S6 & & & S7 & & & S8 & & & S9 & & & S10 & \\
\hline S1 & 0,00 & 0,00 & 0,00 & 0,00 & 0,25 & 0,50 & 0,50 & 0,75 & 1,00 & 0,50 & 0,75 & 1,00 & 0,25 & 0,50 & 0,75 & 0,00 & 0,25 & 0,50 & 0,00 & 0,25 & 0,50 & 0,00 & 0,00 & 0,25 & 0,00 & 0,00 & 0,25 & 0,00 & 0,00 & 0,25 \\
\hline S2 & 0,75 & 1,00 & 1,00 & 0,00 & 0,00 & 0,00 & 0,00 & 0,00 & 0,25 & 0,25 & 0,50 & 0,75 & 0,75 & 1,00 & 1,00 & 0,25 & 0,50 & 0,75 & 0,25 & 0,50 & 0,75 & 0,00 & 0,00 & 0,25 & 0,25 & 0,50 & 0,75 & 0,00 & 0,25 & 0,50 \\
\hline S3 & 0,00 & 0,00 & 0,25 & 0,00 & 0,00 & 0,25 & 0,00 & 0,00 & 0,00 & 0,50 & 0,75 & 1,00 & 0,00 & 0,00 & 0,25 & 0,00 & 0,00 & 0,25 & 0,75 & 1,00 & 1,00 & 0,00 & 0,00 & 0,25 & 0,50 & 0,75 & 1,00 & 0,00 & 0,00 & 0,25 \\
\hline S4 & 0,00 & 0,00 & 0,25 & 0,00 & 0,00 & 0,25 & 0,00 & 0,00 & 0,25 & 0,00 & 0,00 & 0,00 & 0,00 & 0,00 & 0,25 & 0,00 & 0,00 & 0,25 & 0,75 & 1,00 & 1,00 & 0,00 & 0,00 & 0,25 & 0,25 & 0,50 & 0,75 & 0,00 & 0,00 & 0,25 \\
\hline S5 & 0,50 & 0,75 & 1,00 & 0,50 & 0,75 & 1,00 & 0,25 & 0,50 & 0,75 & 0,00 & 0,00 & 0,25 & 0,00 & 0,00 & 0,00 & 0,00 & 0,25 & 0,50 & 0,50 & 0,75 & 1,00 & 0,25 & 0,50 & 0,75 & 0,75 & 1,00 & 1,00 & 0,00 & 0,00 & 0,25 \\
\hline S6 & 0,00 & 0,00 & 0,25 & 0,00 & 0,00 & 0,25 & 0,00 & 0,00 & 0,25 & 0,75 & 1,00 & 1,00 & 0,00 & 0,25 & 0,50 & 0,00 & 0,00 & 0,00 & 0,75 & 1,00 & 1,00 & 0,00 & 0,00 & 0,25 & 0,00 & 0,25 & 0,50 & 0,00 & 0,00 & 0,25 \\
\hline S7 & 0,00 & 0,00 & 0,25 & 0,00 & 0,00 & 0,25 & 0,25 & 0,50 & 0,75 & 0,00 & 0,00 & 0,25 & 0,25 & 0,50 & 0,75 & 0,00 & 0,00 & 0,25 & 0,00 & 0,00 & 0,00 & 0,00 & 0,25 & 0,50 & 0,25 & 0,50 & 0,75 & 0,75 & 1,00 & 1,00 \\
\hline S8 & 0,00 & 0,00 & 0,25 & 0,25 & 0,50 & 0,75 & 0,25 & 0,50 & 0,75 & 0,00 & 0,00 & 0,25 & 0,25 & 0,50 & 0,75 & 0,00 & 0,00 & 0,25 & 0,50 & 0,75 & 1,00 & 0,00 & 0,00 & 0,00 & 0,00 & 0,00 & 0,25 & 0,25 & 0,50 & 0,75 \\
\hline S9 & 0,00 & 0,00 & 0,25 & 0,75 & 1,00 & 1,00 & 0,00 & 0,00 & 0,25 & 0,00 & 0,00 & 0,25 & 0,50 & 0,75 & 1,00 & 0,00 & 0,00 & 0,25 & 0,75 & 1,00 & 1,00 & 0,00 & 0,00 & 0,25 & 0,00 & 0,00 & 0,00 & 0,25 & 0,50 & 0,75 \\
\hline S10 & 0,00 & 0,00 & 0,25 & 0,25 & 0,50 & 0,75 & 0,25 & 0,50 & 0,75 & 0,00 & 0,00 & 0,25 & 0,75 & 1,00 & 1,00 & 0,00 & 0,00 & 0,25 & 0,25 & 0,50 & 0,75 & 0,25 & 0,50 & 0,75 & 0,25 & 0,50 & 0,75 & 0,00 & 0,00 & 0,00 \\
\hline
\end{tabular}

Tablo 5. Bulanık direk ilişki matrisi

\begin{tabular}{|c|c|c|c|c|c|c|c|c|c|c|c|c|c|c|c|c|c|c|c|c|c|c|c|c|c|c|c|c|c|c|}
\hline \multirow[b]{2}{*}{ S1 } & \multirow[b]{2}{*}{0,00} & \multicolumn{2}{|l|}{ S1 } & \multicolumn{3}{|c|}{ S2 } & \multicolumn{2}{|c|}{ S3 } & \multicolumn{3}{|c|}{ S4 } & \multicolumn{3}{|c|}{ S5 } & \multicolumn{3}{|c|}{ S6 } & \multicolumn{3}{|c|}{ S7 } & \multicolumn{4}{|c|}{ S8 } & \multicolumn{3}{|c|}{ S9 } & \multicolumn{3}{|c|}{ S10 } \\
\hline & & 0,00 & 0,00 & 0,11 & 0,29 & 0,54 & 0,25 & 0,46 & 0,71 & 0,39 & 0,61 & 0,82 & 0,32 & 0,57 & 0,79 & 0,11 & 0,36 & 0,61 & 0,21 & 0,43 & 0,64 & 0,32 & 0,54 & 0,75 & 0,43 & 0,64 & 0,86 & 0,36 & 0,57 & 0,79 \\
\hline S2 & 0,64 & 0,89 & 1,00 & & 0,00 & 0,00 & 0,11 & 0,25 & 0,50 & 0,25 & 0,50 & 0,75 & 0,64 & 0,89 & 1,00 & & 0,43 & 0,64 & 0,46 & 0,71 & 0,93 & 0,04 & 0,18 & 0,43 & 0,54 & 0,79 & 0,96 & 0,29 & 0,54 & 0,79 \\
\hline S3 & 0,00 & 0,07 & 0,32 & 0,00 & 0,04 & 0,29 & 0,00 & 0,00 & 0,00 & 0,46 & 0,71 & 0,89 & 0,07 & 0,21 & 0,46 & 0,14 & 0,25 & 0,46 & 0,64 & 0,89 & 1,00 & 0,21 & 0,39 & 0,64 & 0,43 & 0,68 & 0,93 & 0,04 & 0,11 & 0,36 \\
\hline S4 & 0,00 & 0,07 & 0,32 & 0,07 & 0,21 & 0,46 & 0,04 & 0,14 & 0,39 & 0,00 & 0,00 & 0,00 & 0,04 & 0,14 & 0,39 & 0,00 & 0,07 & 0,32 & 0,36 & 0,57 & 0,75 & 0,04 & 0,11 & 0,36 & 0,36 & 0,61 & 0,86 & 0,21 & 0,39 & 0,64 \\
\hline S5 & 0,50 & 0,75 & 0,96 & 0,57 & 0,82 & 1,00 & 0,25 & 0,50 & 0,75 & 0,11 & 0,21 & 0,43 & 0,00 & 0,00 & 0,00 & 0,07 & 0,25 & 0,50 & 0,64 & 0,89 & 1,00 & 0,46 & 0,71 & 0,96 & 0,50 & 0,75 & 0,93 & 0,29 & 0,43 & 0,64 \\
\hline S6 & 0,18 & 0,32 & 0,54 & 0,11 & 0,18 & 0,43 & 0,14 & 0,25 & 0,46 & 0,68 & 0,93 & 1,00 & 0,32 & 0,54 & 0,75 & 0,00 & 0,00 & 0,00 & 0,43 & 0,68 & 0,86 & 0,18 & 0,32 & 0,54 & 0,14 & 0,32 & 0,54 & 0,36 & 0,54 & 0,75 \\
\hline S7 & 0,14 & 0,25 & 0,50 & 0,14 & 0,25 & 0,50 & 0,57 & 0,82 & 0,93 & 0,14 & 0,29 & 0,50 & 0,46 & 0,71 & 0,93 & 0,11 & 0,25 & 0,50 & 0,00 & 0,00 & 0,00 & 0,32 & 0,54 & 0,71 & 0,36 & 0,57 & 0,79 & 0,57 & 0,82 & 1,00 \\
\hline S8 & 0,00 & 0,07 & 0,32 & 0,43 & 0,68 & 0,89 & 0,43 & 0,68 & 0,89 & 0,14 & 0,25 & 0,46 & 0,43 & 0,68 & 0,89 & 0,21 & 0,39 & 0,64 & 0,50 & 0,75 & 0,89 & 0,00 & 0,00 & 0,00 & 0,36 & 0,54 & 0,75 & 0,46 & 0,71 & 0,93 \\
\hline S9 & 0,29 & 0,46 & 0,71 & 0,50 & 0,75 & 0,93 & 0,00 & 0,11 & 0,36 & 0,25 & 0,39 & 0,64 & 0,54 & 0,79 & 0,96 & 0,00 & 0,04 & 0,29 & 0,61 & 0,86 & 0,93 & 0,32 & 0,50 & 0,75 & 0,00 & 0,00 & 0,00 & 0,43 & 0,68 & 0,89 \\
\hline S10 & 0,00 & 0,07 & 0,32 & 0,43 & 0,68 & 0,93 & 0,36 & 0,57 & 0,79 & 0,32 & 0,50 & 0,71 & 0,43 & 0,64 & 0,86 & 0,21 & 0,39 & 0,64 & 0,54 & 0,79 & 0,96 & 0,43 & 0,68 & 0,89 & 0,43 & 0,68 & 0,93 & 0,00 & 0,00 & 0,00 \\
\hline
\end{tabular}


Tablo 6. Bulanık normalize edilmiş direk ilişki matrisi

\begin{tabular}{|c|c|c|c|c|c|c|c|c|c|c|c|c|c|c|c|c|c|c|c|c|c|c|c|c|c|c|c|c|c|c|}
\hline & & S1 & & & S2 & & & S3 & & & S4 & & & S5 & & & S6 & & & S7 & & & S8 & & & S9 & & & S10 & \\
\hline S1 & 0,00 & & 0,00 & 0,02 & 0,04 & 0,08 & & ,07 & 0,10 & & ,09 & & & 0,08 & & & 0,05 & 0,09 & & 0,06 & 0,09 & 0,05 & 0,08 & 0,10 & 0,06 & 0,09 & 0,12 & 0,05 & 0,08 & 0,11 \\
\hline S2 & 0,09 &, 12 & 0,14 & 0,00 & 0,00 & 0,00 & 0,02 & 0,04 & 0,07 & & 0,07 & 0,10 & & 0,12 & & 0,03 & 0,06 & 0,09 & 0,07 & 0,10 & 0,13 & 0,01 & 0,03 & 0,06 & 0,08 & 0,11 & 0,13 & 0,04 & 0,08 & 0,11 \\
\hline S3 & 0,00 & 0,01 & 0,05 & 0,00 & 0,01 & 0,04 & 0,00 & 0,00 & 0,00 & 0,07 & 0,10 & 0,12 & 0,01 & 0,03 & 0,07 & 0,02 & 0,04 & 0,07 & 0,09 & 0,12 & 0,14 & 0,03 & 0,06 & 0,09 & 0,06 & 0,10 & 0,13 & 0,01 & 0,02 & 0,05 \\
\hline S4 & 0,00 & 0,01 & 0,05 & 0,01 & 0,03 & 0,07 & 0,01 & 0,02 & 0,06 & 0,00 & 0,00 & 0,00 & 0,01 & 0,02 & 0,06 & 0,00 & 0,01 & 0,05 & 0,05 & 0,08 & 0,10 & 0,01 & 0,02 & 0,05 & 0,05 & 0,09 & 0,12 & 0,03 & 0,06 & 0,09 \\
\hline S5 & 0,07 & 0,10 & 0,13 & 0,08 & 0,11 & 0,14 & 0,0 & 0,07 & 0,10 & 0,02 & 0,03 & 0,06 & 0,00 & 0,00 & 0,00 & 0,01 & 0,04 & 0,07 & 0,09 & 0,12 & 0,14 & 0,07 & 0,10 & 0,13 & 0,07 & 0,10 & 0,13 & 0,04 & 0,06 & 0,09 \\
\hline S6 & 0,03 & 0,05 & 0,08 & 0,02 & 0,03 & 0,06 & 0,02 & 0,04 & 0,07 & 0,10 & 0,13 & 0,14 & 0,05 & 0,08 & 0,10 & 0,00 & 0,00 & 0,00 & 0,06 & 0,10 & 0,12 & 0,03 & 0,05 & 0,08 & 0,02 & 0,05 & 0,08 & 0,05 & 0,08 & 0,10 \\
\hline S7 & 0,02 & 0,04 & 0,07 & 0,02 & 0,04 & 0,07 & 0,08 & 0,11 & 0,13 & 0,02 & 0,04 & 0,07 & 0,07 & 0,10 & 0,13 & 0,02 & 0,04 & 0,07 & 0,00 & 0,00 & 0,00 & 0,05 & 0,08 & 0,10 & 0,05 & 0,08 & 0,11 & 0,08 & 0,11 & 0,14 \\
\hline S8 & 0,00 & 0,01 & 0,05 & 0,06 & 0,10 & 0,12 & 0,06 & 0,10 & 0,12 & 0,02 & 0,04 & 0,07 & 0,06 & 0,10 & 0,12 & 0,03 & 0,06 & 0,09 & 0,07 & 0,10 & 0,12 & 0,00 & 0,00 & 0,00 & 0,05 & 0,08 & 0,10 & 0,07 & 0,10 & 0,13 \\
\hline S9 & 0,04 & 0,07 & 0,10 & 0,07 & 0,10 & 0,13 & 0,00 & 0,02 & 0,05 & 0,04 & 0,06 & 0,09 & 0,08 & 0,11 & 0,13 & 0,00 & 0,01 & 0,04 & 0,09 & 0,12 & 0,13 & 0,05 & 0,07 & 0,10 & 0,00 & 0,00 & 0,00 & 0,06 & 0,10 & 0,12 \\
\hline S10 & 0,00 & 0,01 & 0,05 & 0,06 & 0,10 & 0,13 & 0,05 & 0,08 & 0,11 & 0,05 & 0,07 & 0,10 & 0,06 & 0,09 & 0,12 & 0,03 & 0,06 & 0,09 & 0,08 & 0,11 & 0,13 & 0,06 & 0,10 & 0,12 & 0,06 & 0,10 & 0,13 & 0,00 & 0,00 & 0,00 \\
\hline
\end{tabular}

Tablo 7. Bulanık toplam ilişki matrisi

\begin{tabular}{|c|c|c|c|c|c|c|c|c|c|c|c|c|c|c|c|c|c|c|c|c|c|c|c|c|c|c|c|c|c|c|}
\hline & & S1 & & & S2 & & & S3 & & & S4 & & & S5 & & & S6 & & & S7 & & & S8 & & & S9 & & & S10 & \\
\hline S1 & & 0,07 &, 55 & & 14 & 0,73 & & 15 & 0,72 & & 0,17 & & & 0,19 & & & 0,10 & & & 0,21 & 0,92 & ,, 06 & 0,17 & 0,76 & 0,09 & 0,21 & 0,91 & 0,07 & 0,19 & 0,83 \\
\hline S2 & 011 & 0,20 & 0,73 & & 10 & 0,71 & 0,04 & 0,14 & 0,75 & 006 & 0,18 & 0,80 & & 0,26 & 0,94 & & 0,12 & 0,62 & & 0,27 & 1,02 & 0,03 & 0,14 & 0,77 & 011 & 0,25 & 0,99 & 007 & 0,20 & 0,89 \\
\hline S3 & 0,01 & 0,06 & 0,50 & 0,02 & 0,08 & 0,58 & 0,02 & 0,07 & 0,52 & 0,08 & 0,16 & 0,64 & 0,03 & 0,12 & 0,68 & 0,03 & 0,07 & 0,47 & 0,11 & 0,22 & 0,82 & 0,04 & 0,12 & 0,62 & 0,08 & 0,18 & 0,77 & 0,03 & 0,10 & 0,65 \\
\hline S4 & 0,01 & 0,05 & 0,44 & 0,02 & 0,08 & 0,54 & 0,01 & 0,07 & 0,51 & 0,01 & 0,05 & 0,47 & 0,02 & 0,09 & 0,60 & 0,00 & 0,04 & 0,40 & 0,06 & 0,16 & 0,70 & 0,02 & 0,07 & 0,52 & 0,06 & 0,15 & 0,68 & 0,04 & 0,12 & 0,61 \\
\hline S5 & 0,09 & 0,19 & 0,74 & & 0,22 & 0,86 & 0,06 & 0,18 & 0,80 & 0,04 & 0,14 & 0,78 & 0,04 & 0,15 & 0,85 & 0,02 & 0,10 & 0,63 & & 0,29 & 1,06 & 0,09 & 0,21 & 0,86 & 0,11 & 0,25 & 1,01 & 0,08 & 0,20 & 0,90 \\
\hline S6 & 0,04 & 0,10 & 0,57 & & 0,11 & 0,65 & 0,04 & 0,12 & 0,63 & 0,11 & 0,20 & 0,71 & 0,07 & 0,17 & 0,77 & 0,01 & 0,05 & & 0,09 & 0,22 & 0,86 & 0,04 & 0,13 & 0,66 & 0,05 & 0,16 & 0,79 & 0,07 & 0,17 & 0,75 \\
\hline S7 & 0,04 & 0,10 & 0,61 & 0,05 & 0,13 & 0,72 & 0,10 & 0,20 & 0,74 & 0,04 & 0,14 & 0,71 & 0,09 & 0,21 & 0,86 & 0,03 & 0,09 & 0,56 & 0,04 & 0,16 & 0,84 & 0,07 & 0,17 & 0,75 & 0,08 & 0,21 & 0,89 & 0,10 & 0,22 & 0,85 \\
\hline S8 & 0,02 & 0,09 & 0,62 & & 0,19 & 0,80 & & 0,19 & 0,77 & & 0,14 & & & 0,22 & & & 0,11 & & & 0,26 & & & & 0,69 & & 0,21 & 0,93 & 0,09 & 0,21 & 0,87 \\
\hline S9 & 0,06 & 0,14 & 0,66 & 0,09 & 0,20 & 0,79 & 0,03 & 0,12 & 0,70 & 0,06 & 0,15 & 0,74 & 0,11 & 0,24 & 0,89 & 0,01 & 0,07 & 0,55 & 0,12 & 0,27 & 0,97 & & 0,17 & 0,77 & & 0,14 & 0,82 & 0,09 & 0,21 & 0,86 \\
\hline S10 & 0,02 & 0,09 & 0,64 & 0,08 & 0,20 & 0,83 & 0,07 & 0,18 & 0,78 & 0,07 & 0,17 & 0,79 & 0,09 & 0,22 & 0,93 & 0,04 & 0,12 & 0,63 & 0,12 & 0,27 & 1,03 & 0,08 & 0,19 & 0,83 & 0,09 & 0,23 & 0,98 & 0,03 & 0,13 & 0,79 \\
\hline
\end{tabular}


5. Adım: Etkileyen ve etkilenen kriter gruplarının belirlenmesi

Tablo 8'de verilen durulaştırılmış toplam ilişki matrisinden yola çıkarak yöntemin esasını oluşturan satır ve sütun toplamlarını veren $\tilde{D}^{\text {def }}$ ve $\tilde{R}^{\text {def }}$ değerleri hesaplanmıştır. Bu değerlerden yola çıkarak stratejilerin önem derecesi, etkileyen ve etkilenen gruplar oluşturulmuştur.

6. Adım: Eşik değerin hesaplanması ve etki-ilişki diyagramının elde edilmesi

Stratejiler arasındaki ikili ilişkilerde görece daha önemlileri ortaya koymak adına net sayıya dönüștürülmüş olan durulaştırılmış bulanık toplam ilișki matrisinde bir eşik değer belirlenir. Bu eșik değer uzman görüşleri tarafından belirlenebileceği gibi sayısal yöntemlerden de faydalanılabilir. $\mathrm{Bu}$ çalışmada eşik değer üçüncü kartil değeri olup ve 0,316 olarak hesaplanmıştır. Tablo 8'de eşik değer ve üstü değerler koyu olarak işaretlenmiştir.

Tablo 8. Durulaştırılmış bulanık toplam ilişki matrisi

\begin{tabular}{cccccccccccccc}
\hline & $\mathbf{S 1}$ & $\mathbf{S 2}$ & $\mathbf{S 3}$ & $\mathbf{S 4}$ & $\mathbf{S 5}$ & $\mathbf{S 6}$ & $\mathbf{S 7}$ & $\mathbf{S 8}$ & $\mathbf{S 9}$ & $\mathbf{S 1 0}$ & $\tilde{D}_{i}^{\text {def }}$ & $\tilde{D}_{i}^{\text {def }}+\tilde{R}_{i}^{\text {def }}$ & $\tilde{D}_{i}^{\text {def }}-\tilde{R}_{i}^{\text {def }}$ \\
\hline S1 & 0,152 & 0,238 & 0,250 & 0,273 & 0,305 & 0,184 & $\mathbf{0 , 3 2 4}$ & 0,267 & $\mathbf{0 , 3 2 7}$ & 0,296 & 2,617 & 4,570 & 0,664 \\
$\mathbf{S 2}$ & 0,293 & 0,219 & 0,246 & 0,281 & $\mathbf{0 , 3 6 8}$ & 0,209 & $\mathbf{0 , 3 8 4}$ & 0,250 & $\mathbf{0 , 3 7 0}$ & $\mathbf{0 , 3 1 8}$ & 2,938 & 5,392 & 0,483 \\
S3 & 0,132 & 0,163 & 0,145 & 0,243 & 0,215 & 0,138 & $\mathbf{0 , 3 2 3}$ & 0,208 & 0,282 & 0,198 & 2,047 & 4,407 & $-0,313$ \\
S4 & 0,113 & 0,160 & 0,144 & 0,118 & 0,177 & 0,097 & 0,250 & 0,146 & 0,241 & 0,201 & 1,650 & 4,112 & $-0,813$ \\
S5 & 0,282 & $\mathbf{0 , 3 2 9}$ & 0,285 & 0,254 & 0,272 & 0,194 & $\mathbf{0 , 4 1 1}$ & $\mathbf{0 , 3 1 8}$ & $\mathbf{0 , 3 7 4}$ & 0,315 & 3,034 & 5,985 & 0,082 \\
S6 & 0,183 & 0,203 & 0,206 & 0,290 & 0,277 & 0,115 & $\mathbf{0 , 3 2 6}$ & 0,221 & 0,266 & 0,271 & 2,358 & 4,023 & 0,693 \\
S7 & 0,192 & 0,237 & 0,294 & 0,234 & $\mathbf{0 , 3 2 3}$ & 0,173 & 0,273 & 0,270 & $\mathbf{0 , 3 2 1}$ & $\mathbf{0 , 3 2 3}$ & 2,641 & 6,080 & $-0,798$ \\
S8 & 0,183 & 0,296 & 0,289 & 0,241 & $\mathbf{0 , 3 3 3}$ & 0,199 & $\mathbf{0 , 3 7 7}$ & 0,207 & $\mathbf{0 , 3 3 0}$ & $\mathbf{0 , 3 2 4}$ & 2,778 & 5,242 & 0,315 \\
S9 & 0,232 & 0,304 & 0,219 & 0,251 & $\mathbf{0 , 3 4 4}$ & 0,152 & $\mathbf{0 , 3 8 0}$ & 0,274 & 0,257 & $\mathbf{0 , 3 2 0}$ & 2,734 & 5,856 & $-0,388$ \\
S10 & 0,190 & 0,304 & 0,282 & 0,277 & $\mathbf{0 , 3 3 8}$ & 0,204 & $\mathbf{0 , 3 9 0}$ & 0,302 & $\mathbf{0 , 3 5 4}$ & 0,243 & 2,885 & 5,695 & 0,075 \\
$\tilde{R}_{i}^{d e f}$ & 1,953 & 2,455 & 2,360 & 2,463 & 2,952 & 1,665 & 3,439 & 2,463 & 3,122 & 2,810 & & & \\
\hline
\end{tabular}

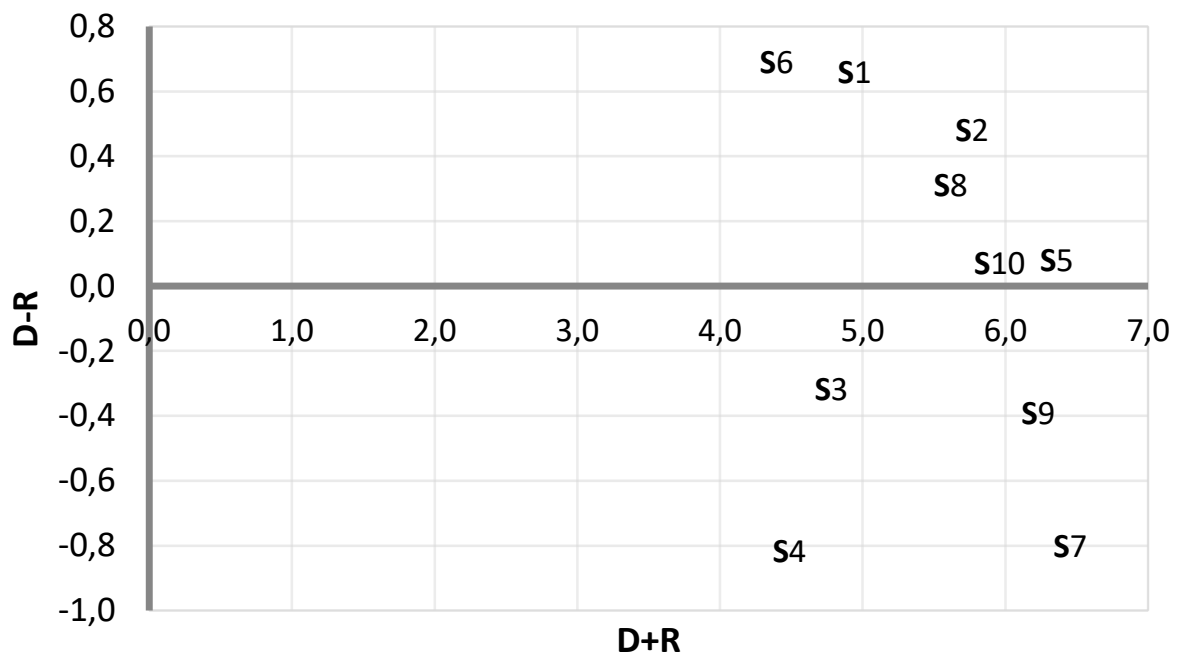

Şekil 1. Neden-Sonuç diyagramı

Tablo 8'den yararlanılarak elde edilen $\tilde{D}_{i}^{\text {def }}+\tilde{R}_{i}^{\text {def }}$ ve $\tilde{D}_{i}^{\text {def }}-\tilde{R}_{i}^{\text {def }}$ değerleri ile Şekil 1'deki neden sonuç diyagramı oluşturulmuştur. Bu diyagramda görüleceği üzere kriterler arası ilişkiler ağı bütün bir sistem olarak düşünüldüğünde, kriterlerin önem sırasını gösteren $\tilde{D}_{i}^{d e f}+\tilde{R}_{i}^{\text {def }}$ değerleri içerisinden en yüksek değere sahip olan çevikliğin artırılması (S7), iş birliğinin artırılması (S5), risklerin paylaşılması 
(S9) ve tedarikçi seçimi ve geliştirilmesi (S10) stratejilerinin diğer stratejilerle daha çok ilişkide olduğu görülmektedir. İşletmenin bu stratejilerin uygulanmasında göstereceği önem, tedarik zincirinde karşı karşıya kalacağı riskleri azaltmaya yardımcı olacaktır.

Diğer stratejilerle en fazla ilişkiye sahip strateji olarak çeviklik, belirsiz ve sürekli değişen iş ortamlarında faaliyet gösteren işletme için baskın rekabet aracı olarak belirmektedir [82]. İşletmelerin rekabet avantajını sürdürebilmeleri ve risklere karşı daha güçlü olabilmelerinin tedarik zincirlerindeki çevikliğin geliştirilmesine bağlı olduğu literatürde de çeşitli çalışmalarda vurgulanmaktadır [38], [83], [84].

Savunma sanayisindeki işletmelerin çok çeşitli bileşenlerden oluşan yüksek teknolojiye sahip ürünler üretmesi çok sayıda tedarikçiyle çalışmasını gerektirmektedir. Çalışma yapılan işletmenin de müşteri taleplerine göre değişen özelliklerde karmaşık yapıya sahip zırhlı muharebe araçları üretiyor olması, çok sayıda tedarikçiyle çalışmasına neden olmuştur. $\mathrm{Bu}$ da tedarik zincirinin her aşamasında maliyetleri ve riskleri kontrol edebilmek için firmanın zincir ortaklarıyla iş birliğine eğilmesini zorunlu kılmaktadır. Bu bulguyu teyit edecek şekilde, tedarik zinciri risk yönetimi kapsamında iş birliği stratejisinin önemine vurgu yapan çalışmalar bulunmaktadır [20], [27], [33], [85], [86].

Genellikle dış kaynak kullanımı şeklinde ortaya çıkan ve tedarik zinciri ortaklarıyla yapılan sözleşmelerle risk maliyetlerinin paylaşılması veya transferini içeren risk paylaşımı stratejisi önem derecesi bakımından üçüncü sırada yer almaktadır. Risk paylaşımının firmanın uzun dönemde elde edeceği karı etkileyen oldukça güçlü bir risk azaltma stratejisi olduğu başka yazarlar tarafından da belirtilmiştir [87].

Dördüncü sırada yer alan tedarikçi seçimi ve geliştirme stratejisi odak işletmenin belirsizliklere ve değişimlere zamanında ve doğru tepkiler verebilmesi bakımından kritik öneme sahip olup literatürde bu bulguyu destekleyen diğer bazı çalışmalar da bulunmaktadır [88].

Şekil 1'de pozitif net değere sahip $\tilde{D}_{i}^{\text {def }}-\tilde{R}_{i}^{\text {def }}$ değerlerine bakıldığında sırasıyla standartlaştırma/ortak parça kullanımı (S6), talep tahmininin doğru yapılması (S1), bilgi paylaşımı (S2), yerel tedarikçilerle çalışılması (S8), işbirliğinin artırılması (S5) ve tedarikçi seçimi ve tedarikçi geliştirme (S10) stratejilerinin diğer stratejileri daha çok etkileyen konumunda olduğu görülmektedir.

Parça çeşitliliğinin azalmasını sağlayarak, işlemsel verimliliği arttıran, stok yönetimini kolaylaştıran ve ölçek ekonomisi sayesinde maliyetleri düşüren standartlaştırma/ortak parça kullanımının diğer stratejileri en fazla etkileyen strateji olduğu görülmektedir. Ayrıca, bu stratejiyi en fazla çeviklik, stok bulundurma ve iş birliği stratejilerinin etkilediği görülmektedir.

İkinci sırada talep risklerinin azaltılmasında etkili olan doğru talep tahminlerinin yapılması yer alırken, üçüncü sırada ise bilgi paylaşımı stratejisi yer almıştır. Doğru talep tahmini stratejisinin özellikle risk paylaşımı, çeviklik ve iş birliği stratejilerini daha fazla etkilemekte olması firmanın tedarik zinciri ortaklarıyla birlikte doğru tahminler yapmasını gerekli kılmaktadır. Bilgi paylaşımı stratejisi özellikle çeviklik, risk paylaşımı ve iş birliği gibi risk azaltma stratejilerini etkilemektedir çünkü bu stratejilerin başarılı bir şekilde uygulanması etkin bilgi paylaşımını gerektirmektedir [32], [89], [90].

Şekil 1'de $\tilde{D}_{i}^{\text {def }}-\tilde{R}_{i}^{\text {def }}$ değerlerine bakıldığında sırasıyla negatif değere sahip olan stok bulundurma (S4), çevikliğin artırılması (S7), risklerin paylaşılması (S9) ve esnek taşımacılık (S3) stratejilerinin en çok etkilenen ya da en az etkiye sahip stratejiler olduğunu söylemek mümkündür.

Diğer stratejilerden en çok etkilenen stratejilerin başında stok bulundurma yer almaktadır. Stok tutmak [30] veya tedarikçilere stok tutturmak [17] ileriki zamanlarda beklenen dönemsel kriz durumlarına karşı alınan bir önlem olarak uygulanmaktadır. Özellikle standartlaştırılmış/ortaklaştırılmış ürün 
sayısının arttırılması, talep tahminin doğru bir şekilde yapılması, bilgi paylaşımı ve doğru tedarikçi seçimi gibi stratejilerin uygulanmasındaki başarı veya başarısızlık stok bulundurma kararlarını etkileyebilmektedir.

En önemli stratejiler içerisinde ilk sırada yer alan çeviklik etkilenen stratejiler içerisinde ikinci sırada yer almaktadır. Bu bulgu çevik olabilmenin diğer strateji uygulamalarını yerine getirmeye bağlı olduğu şeklinde yorumlanabilmektedir. Çeviklik konusunda, yöneticilerin özellikle iş birliğinin artırılması ve tedarikçi seçme ve geliştirme stratejilerine eğilmeleri önem taşımaktadır. Çünkü bu stratejilerin çeviklik üzerinde önemli etkileri bulunmaktadır.

En çok etkilenen diğer bir strateji olan risk paylaşımı stratejisinin, birlikte çalışılan firmalarla işbirliği içerisinde olmayı ve etkin bilgi paylaşımını gerektirmektedir. Risk paylaşım stratejisinin en çok etkilendiği stratejiler arasında çeviklik, işbirliği, tedarikçi seçme ve geliştirme stratejileri bulunmaktadir.

En çok etkilenen stratejilerden sonuncusu esnek taşımacılık stratejisidir. Esnek taşımacılık genellikle lojistik hizmet sağlayıcılar tarafından gerçekleştirilmekte olup dış kaynak kullanımı ile elde edilmektedir. Esnek taşımacılık stratejisini seçen firmalar aynı zamanda riski de paylaşmış olmaktadırlar. Risk paylaşımı yanında, çeviklik ve stok bulundurma stratejileri de esnek taşımacılığı etkilemektedir.

\section{V.SONUC}

Savunma sanayisindeki işletmelerin yüksek teknolojili ürünler üretmesi, çok sayıda alt bileşenden oluşan sistemler geliştirmeleri, özel kalite standartları uygulamaları ve çok çeşitli müşteri taleplerini karşılama zorunlulukları tedarik zincirlerinin risklere karşı hassasiyetini arttırmaktadır. Bu nedenle bu iş kolundaki firmaların riskleri veya risklerin olumsuz etkilerini azaltacak uygun stratejileri belirlemeleri günümüzün yoğun rekabet ortamındaki başarıları bakımından önemlidir. Uygun risk azaltma stratejilerinin belirlenmesinde dikkate alınacak konulardan birisi de bu stratejilerin birbirleri arasındaki nedensellik ilişkileridir. Bu bağlamda, çalışmada Türkiye savunma sanayinde faaliyet gösterten bir işletmede en önemli stratejiler ve stratejiler arasındaki ilişkiler uzman görüşlerinin bulanık DEMATEL yöntemiyle analiz edilmesi neticesinde tespit edilmiştir.

$\mathrm{Bu}$ çalışmanın bulguları savunma sanayinde faaliyet gösteren firmalara tedarik zincirlerinde karşı karşıya kaldıkları riskleri minimize edebilmeleri için bir takım çıkarımlarla birlikte önerilerde bulunma imkânı vermektedir.

Müşteri taleplerindeki değişkenliğin yüksek olması işletmelerin elinde bulundurdukları rekabet avantajının korunabilmesi için taleplere hızlı cevap vermeyi gerektirmekte, bu da çevik olmayı zorunlu k1lmaktadır.

Tedarik zincirindeki ortakların operasyonları geliștirmek için birlikte çalıșmaları, odak işletmenin tedarik zincirinin diğer üyelerinin gelişimine katkı sağlaması ve karşılaşılacak çeşitli risklere karșı iş birliği içerisinde olmaları tedarik zinciri faaliyetlerinin kesintiye uğramasını engelleyerek sadece odak işletmenin değil tüm tedarik zinciri ortaklarının kazançlı çıkmasını sağlayacaktır.

Birçok işletme kararı için temel teşkil eden talep tahminlerinin doğru bir şekilde yapılması savunma sanayindeki firmalar için de önemlidir. Bu bağlamda, tedarik zinciri ortaklarıyla işbirliği içerisinde tahmine imkan veren tahmin mekanizmaları kurulmalıdır. Ayrıca, talep tahmininde satış noktalarından gelen anlık bilgiler gibi ancak teknolojik araçların kullanımıyla mümkün olan yöntemler kullanılmalıdır. 
Riski veya etkilerini azaltmada karşımıza çıkan diğer bir strateji bilgi paylaşımıdır. Savunma sanayindeki firmaların zincirdeki ortaklarıyla bilgiyi etkin bir şekilde paylaşabilecekleri teknik ve sosyal sistemleri tesis etmeleri önem taşımaktadır. Bilgi paylaşımının sadece teknolojiyle mümkün olmayacağı, ama aynı zamanda zincir ortakları arasında güven gibi sosyal bir boyutunun da olduğu dikkate alınmalıdır.

Her ne kadar savunma sanayindeki firmalar müşteri isteklerinin karşılanmasında terzi usulü çözümler geliştiriliyor olsalar da riski azaltma özelliği nedeniyle belirli ölçülerde standartlaşma/ortak parça kullanımının önemini yitirmediği görülmektedir. Sektör firmaları mümkün oldukça standartlaştırma/ortak parça kullanımı stratejisini kullanmalıdırlar.

Savunma sanayindeki işletmelerin diğer stratejileri uygulamada gösterdikleri başarı stok bulundurma ihtiyacını azaltmaktadır. Bu bulgu aynı zamanda savunma sanayisindeki işletmelerin stok seviyelerini düşük seviyede tutmak isteseler de diğer stratejilerin uygulanmasında yaşanacak sorunlara karşı belirli düzeyde stok bulundurmaları gerektiği şeklinde de yorumlanabilir. Bununla birlikte, stok bulundurma ile stok bulundurmanın ilişkili olduğu stratejilerin doğrudan ve dolaylı maliyetleri karşılaştırılarak daha doğru kararlar verilebilir.

Çalışmanın alanında ilk olması yansıra her çalışmada olduğu gibi bazı kısıtları da bulunmaktadır. Bunlardan ilki, karmaşıklığı önlemek ve cevapların güvenilirliğini artırmak için sadece 10 adet stratejinin değerlendirmeye alınmış olmasıdır. Diğer bir kısıt ise çalışmanın sadece bir işletmede gerçekleştirilmiş olması ve bunun da sonuçların genelleştirilmesini zorlaştırmasıdır. Gelecekteki çalışmalar farklı sektörleri, daha fazla sayıda stratejiyi ve daha fazla işletmeyi dâhil edecek şekilde tasarlanabilir. Ayrıca, bulanık DEMATEL yönteminin yanı sıra başka yöntemlerin de kullanılacağı ve sonuçları karşılaştırma imkânı veren çalışmalar yapılması da literatürü zenginleştirecek ve uygulamacılara yol gösterecektir.

\section{KAYNAKLAR}

[1] C. S. Tang, "Perspectives in supply chain risk management," International Journal of Production Economics, vol. 103, no. 2, pp. 451-488, 2006.

[2] P. S. Ceryno, L. F. Scavarda, ve K. Klingebiel, "Supply chain risk: Empirical research in the automotive industry,” Journal of Risk Research, vol. 18, no. 9, pp. 1145-1164, 2015.

[3] J. H. Thun and D. Hoenig, "An empirical analysis of supply chain risk management in the German automotive industry," International Journal of Production Economics, vol. 131, no. 1, pp. 242-249, 2011.

[4] A. Wieland and C. Marcus Wallenburg, "Dealing with supply chain risks: Linking risk management practices and strategies to performance," International Journal of Physical Distribution and Logistics Management, vol. 42, no. 10, pp. 887-905, 2012.

[5] W. Ho, T. Zheng, H. Yildiz, and S. Talluri, "Supply chain risk management: A literature review," International Journal of Production Research, vol. 53, no. 16, pp. 5031-5069, 2015.

[6] J. Hallikas, I. Karvonen, U. Pulkkinen, V. M. Virolainen, and M. Tuominen, "Risk management processes in supplier networks," International Journal of Production Economics, vol. 90, no. 1 , pp. 47-58, 2004.

[7] G. Tuncel and G. Alpan, "Risk assessment and management for supply chain networks: A case study," Computers in Industry, vol. 61, no. 3, pp. 250-259, 2010. 
[8] B. Tomlin, "On the value of mitigation and contingency strategies for managing supply chain disruption risks," Management Science, vol. 52, no. 5, pp. 639-657, 2006.

[9] D. Kern, R. Moser, E. Hartmann, and M. Moder, "Supply risk management: Model development and empirical analysis," International Journal of Physical Distribution \& Logistics Management, vol. 42, no. 1, pp. 60-82, 2012.

[10] R. Rajesh, V. Ravi, and R. Venkata Rao, "Selection of risk mitigation strategy in electronic supply chains using grey theory and digraph-matrix approaches," International Journal of Production Research, vol. 53, no. 1, pp. 238-257, 2015.

[11] R. C. Banlaoi, "Globalization's impact on defence industry in Southeast Asia," in Globalization and Defence in the Asia-Pacific, New York, USA: Routledge, 2009, pp. 194-218.

[12] Y. Küçükseyhan, "Türkiye savunma sanayi sektör raporu,” Türkiye Odalar ve Borsalar Birliği Savunma Sanayi Sektör Meclisi, Türkiye, 2017.

[13] A. Rahimi, A. Raad, A. Alem Tabriz, and A. Motameni, "Providing an interpretive structural model of agile supply chain practices," Journal of Modelling in Management, vol. 15, no. 21, pp. 661684, 2019.

[14] M. Essig, S. Tandler and M. Scheckenhofer, "Defence supply chain management: Conceptual framework and first empirical findings," in Public Procurement Proceedings of the International Public Procurement Conference (IPPC), 2010, pp. 1-31.

[15] N. Perlekar and J. J. Thakkar, "Risk management framework for outsourcing in the defence sector: A case from India," International Journal of Production Research, vol. 57, no. 18, pp. 58925919, 2019.

[16] S. Maiti. (2018, February 20). Supply Chain Management in Aerospace and Defense [Online]. Available: https://www.ey.com/Publication/vwLUAssets/ey-ad-edge-supply-chain-management-inaerospace-and-defense/\$File/ey-ad-edge-supply-chain-management-in-aerospace-and-defense.pdf

[17] W. Chang, A. E. Ellinger, and J. Blackhurst, "A contextual approach to supply chain risk mitigation," International Journal of Logistics Management, vol. 26, no. 3, pp. 642-656, 2015.

[18] Y. Fan and M. Stevenson, "A review of supply chain risk management: definition, theory, and research agenda," International Journal of Physical Distribution \& Logistics Management, vol. 48, no. 3, pp. 205-230, 2018.

[19] S. Chopra and M. M. S. Sodhi, "Managing risk to avoid: Supply-chain breakdown," MIT Sloan Management Review, vol. 46, no. 1, pp. 52-61, 2004.

[20] U. Jüttner, H. Peck, and M. Christopher, "Supply chain risk management: outlining an agenda for future research," International Journal of Logistics Research and Applications, vol. 6, no. 4, pp. 197-210, 2003.

[21] C. S. Tang, "Robust strategies for mitigating supply chain disruptions," International Journal of Logistics Research and Applications, vol. 9, no. 1, pp. 33-45, 2006.

[22] I. Manuj and J. T. Mentzer, "Global supply chain risk management," Journal of Business Logistics, vol. 29, no. 1, pp. 133-155, 2008. 
[23] R. Rajesh and V. Ravi, "Modeling enablers of supply chain risk mitigation in electronic supply chains: A grey-DEMATEL approach," Computers and Industrial Engineering, vol. 87, pp. 126-139, 2015.

[24] S. Li, S. S. Rao, T. S. Ragu-Nathan, and B. Ragu-Nathan, "Development and validation of a measurement instrument for studying supply chain management practices," Journal of Operations Management, vol. 23, no. 6, pp. 618-641, 2005.

[25] K. Park, "Flexible and redundant supply chain practices to build strategic supply chain resilience: Contingent and resource-based perspectives," Ph.D. dissertation, Manufacturing and Technology Management, University of Toledo, Ohio, ABD, 2011.

[26] A. S. Kohli and J. B. Jensen, "Assessing effectiveness of supply chain collaboration: An empirical study,” Supply Chain Forum: An International Journal, vol. 11, no. 2, pp. 2-16, 2010.

[27] G. Li, H. Fan, P. K. C. Lee, and T. C. E. Cheng, "Joint supply chain risk management: An agency and collaboration perspective," International Journal of Production Economics, vol. 164, pp. 83-94, 2015.

[28] M. M. Naim, A. T. Potter, R. J. Mason, and N. Bateman, "The role of transport flexibility in logistics provision," International Journal of Logistics Management, vol. 17, no. 3, pp. 297-311, 2006.

[29] I. N. Pujawan, "Assessing supply chain flexibility: A conceptual framework and case study," International Journal of Integrated Supply Management, vol. 1, no. 1, pp. 79-97, 2004.

[30] E. M. Tachizawa and C. Gimenez, "Assessing the effectiveness of supply flexibility sources: An empirical research," International Journal of Production Research, vol. 47, no. 20, pp. 5791-5809, 2009.

[31] T. M. Simatupang and R. Sridharan, "An integrative framework for supply chain collaboration," International Journal of Logistics Management, vol. 16, no. 2, pp. 257-274, 2005.

[32] M. Cao, M. A. Vonderembse, Q. Zhang, and T. S. Ragu-Nathan, "Supply chain collaboration: Conceptualisation and instrument development," International Journal of Production Research, vol. 48, no. 22, pp. 6613-6635, 2010.

[33] J. Chen, A. S. Sohal, and D. I. Prajogo, "Supply chain operational risk mitigation: A collaborative approach," International Journal of Production Research, vol. 51, no. 7, pp. 2186-2199, 2013.

[34] A. Ç. Buran, "Tedarik zinciri risklerinin azaltılmasında işbirliği yaklaşımı: Üretim işletmelerinde bir araştırma," Doktora tezi, İşletme Bölümü, Dumlupınar Üniversitesi, Kütahya, Türkiye, 2016.

[35] B. Baud-Lavigne, B. Agard, and B. Penz, "Mutual impacts of product standardization and supply chain design," International Journal of Production Economics, vol. 135, no. 1, pp. 50-60, 2012.

[36] N. Sharma, B. S. Sahay, R. Shankar, and P. R. S. Sarma, "Supply chain agility: Review, classification and synthesis," International Journal of Logistics Research and Applications, vol. 20, no. 6, pp. 532-559, 2017. 
[37] X. li, C. Chung, T. J. Goldsby, and C. W. Holsapple, "A unified model of supply chain agility: The work-design perspective," International Journal of Logistics Management, vol. 19, no. 3, pp. 408-435, 2008.

[38] M. J. Braunscheidel and N. C. Suresh, "The organizational antecedents of a firm's supply chain agility for risk mitigation and response," Journal of Operations Management, vol. 27, no. 2, pp. 119-140, 2009.

[39] M. Bruce, L. Daly, and N. Towers, "Lean or agile: A solution for supply chain management in the textiles and clothing industry ?," International Journal of Operations and Production Management, vol. 24, no. 1-2, pp. 151-170, 2004.

[40] G. L. Schlegel and R. J. Trent, Supply Chain Risk Management: An Emerging Discipline, 1st ed., Boca Raton, USA: CRC Press, 2015.

[41] Y. Fang and B. Shou, "Managing supply uncertainty under supply chain cournot competition," European Journal of Operational Research, vol. 243, no. 1, pp. 156-176, 2015.

[42] A. Ghadge, S. Dani, R. Ojha, and N. Caldwell, "Using risk sharing contracts for supply chain risk mitigation: A buyer-supplier power and dependence perspective," Computers and Industrial Engineering, vol. 103, pp. 262-270, 2017.

[43] S. Hosseini and K. Barker, "A Bayesian Network Model For resilience-based supplier selection," International Journal of Production Economics, vol. 180, pp. 68-87, 2016.

[44] C. Y. Chiang, C. Kocabasoglu-Hillmer, and N. Suresh, "An empirical investigation of the impact of strategic sourcing and flexibility on firm's supply chain agility," International Journal of Operations and Production Management, vol. 32, no. 1, pp. 49-78, 2012.

[45] A. Golmohammadi and E. Hassini, "Investment strategies in supplier development under capacity and demand uncertainty," Decision Sciences, 2020, doi: doi.org/10.1111/deci.12419.

[46] T. M. Simatupang and R. Sridharan, "The collaborative supply chain," International Journal of Logistics Management, vol. 13, no. 1, pp. 15-30, 2002.

[47] H. L. Lee, V. Padmanabhan, and S. Whang, "Information distortion in a supply chain: The bullwhip effect," Management Science, vol. 50, no. 12, pp. 1875-1886, 2004.

[48] I. Kilubi, "The strategies of supply chain risk management - a synthesis and classification," International Journal of Logistics Research and Applications, vol. 19, no. 6, pp. 604-629, 2016.

[49] S. Talluri, T. J. Kull, H. Yildiz, and J. Yoon, "Assessing the efficiency of risk mitigation strategies in supply chains," Journal of Business Logistics, vol. 34, no. 4, pp. 253-269, 2013.

[50] L. Liu, S. Li, and Y. Wu, "Supply chain risk management in chinese chemical industry based on stochastic chance-constrained programming model," Applied Mathematics and Information Sciences, vol. 8, no. 3, pp. 1201-1206, 2014.

[51] S. K. Sharma and A. Bhat, "Supply chain risks: Development of model and empirical evidence," International Journal of Applied Management Science, vol. 6, no. 1, pp. 45-64, 2014.

[52] F. Aqlan and S. S. Lam, "Supply chain risk modelling and mitigation," International Journal of Production Research, vol. 53, no. 18, pp. 5640-5656, 2015. 
[53] A. Qazi, J. Quigley, A. Dickson, B. Gaudenzi, and Ş. Ö. Ekici, "Cost and benefit analysis of supplier risk mitigation in an aerospace supply chain," in International Conference on Industrial Engineering and Systems Management (IESM), Seville, Spain, 2015, pp. 850-857.

[54] T. J. Kull and S. Talluri, "A supply risk reduction model using integrated multicriteria decision making," IEEE Transactions on Engineering Management, vol. 55, no. 3, pp. 409-419, 2008.

[55] M. D. Sherwin, H. R. Medal, C. A. MacKenzie, and K. J. Brown, "Identifying and mitigating supply chain risks using fault tree optimization," IISE Transactions, vol. 52, no. 2, pp. 236-254, 2020.

[56] C. Tang and B. Tomlin, "The power of flexibility for mitigating supply chain risks," International Journal of Production Economics, vol. 116, no. 1, pp. 12-27, 2008.

[57] M. M. H. Chowdhury and M. A. Quaddus, "A multiple objective optimization based QFD approach for efficient resilient strategies to mitigate supply chain vulnerabilities: The case of garment industry of Bangladesh,” Omega, vol. 57, pp. 5-21, 2015.

[58] A. Gabus and E. Fontela, "World problems, an invitation to further thought within the framework of DEMATEL," Battelle Geneva Research Centre, 1972.

[59] W. W. Wu and Y. T. Lee, "Developing global managers' competencies using the fuzzy DEMATEL method," Expert Systems with Applications, vol. 32, no. 2, pp. 499-507, 2007.

[60] C. W. Hsu, T. C. Kuo, S. H. Chen, and A. H. Hu, "Using DEMATEL to develop a carbon management model of supplier selection in green supply chain management," Journal of Cleaner Production, vol. 56, pp. 164-172, 2013.

[61] R. J. Lin, "Using Fuzzy DEMATEL to evaluate the green supply chain management practices," Journal of Cleaner Production, vol. 40, pp. 32-39, 2013.

[62] G. H. Tzeng, C. H. Chiang, and C. W. Li, "Evaluating intertwined effects in e-learning programs: A novel hybrid mcdm model based on factor analysis and DEMATEL," Expert Systems with Applications, vol. 32, no. 4, pp. 1028-1044, 2007.

[63] M.-L. Tseng, Yuan, H. Lin, M.-L. Tseng, and Y. H. Lin, "Application of fuzzy DEMATEL to develop a cause and effect model of municipal solid waste management in metro manila," Environmental Monitoring and Assessment, vol. 158, pp. 519-533, 2009.

[64] K. Govindan and A. Chaudhuri, "Interrelationships of risks faced by third party logistics service providers: A DEMATEL based approach," Transportation Research Part E: Logistics and Transportation Review, vol. 90, pp. 177-195, 2016.

[65] S. Chirra and D. Kumar, "Evaluation of supply chain flexibility in automobile industry with fuzzy DEMATEL approach," Global Journal of Flexible Systems Management, vol. 19, no. 4, pp. 305-319, 2018.

[66] C. J. Lin and W. W. Wu, "A causal analytical method for group decision-making under fuzzy environment," Expert Systems with Applications, vol. 34, no. 1, pp. 205-213, 2008.

[67] B. Chang, C. W. Chang, and C. H. Wu, "Fuzzy DEMATEL method for developing supplier selection criteria," Expert Systems with Applications, vol. 38, no. 3, pp. 1850-1858, 2011.

[68] Q. Zhou, W. Huang, and Y. Zhang, "Identifying critical success factors in emergency management using a fuzzy DEMATEL method," Safety Science, vol. 49, no. 2, pp. 243-252, 2011. 
[69] W. W. Wu, "Segmenting critical factors for successful knowledge management implementation using the fuzzy DEMATEL method," Applied Soft Computing Journal, vol. 12, no. 1, pp. 527-535, 2012.

[70] S. Altuntas, H. Selim, and T. Dereli, "A fuzzy DEMATEL-based solution approach for facility layout problem: A case study," International Journal of Advanced Manufacturing Technology, vol. 73, no. 5-8, pp. 749-771, 2014.

[71] S. Routroy and C. V. Sunil Kumar, "Analyzing supplier development program enablers using fuzzy DEMATEL,” Measuring Business Excellence, vol. 18, no. 4, pp. 1-26, 2014.

[72] S. Luthra, K. Govindan, R. K. Kharb, and S. K. Mangla, "Evaluating the enablers in solar power developments in the current scenario using fuzzy DEMATEL: An Indian perspective," Renewable and Sustainable Energy Reviews, vol. 63, pp. 379-397, 2016.

[73] M. Tyagi, P. Kumar, and D. Kumar, "Assessment of critical enablers for flexible supply chain performance measurement system using fuzzy DEMATEL approach," Global Journal of Flexible Systems Management, vol. 16, no. 2, pp. 115-132, 2015.

[74] Ü. Özdemir, "Investigation of occupational accidents occurred in ports by using fuzzy DEMATEL and fuzzy TOPSIS methods," Journal of ETA Maritime Science, vol. 4, no. 3, pp. 235$247,2016$.

[75] J. Gopal, A. K. Sangaiah, A. Basu, and X. Z. Gao, "Integration of fuzzy DEMATEL and FMCDM approach for evaluating knowledge transfer effectiveness with reference to GSD project outcome," International Journal of Machine Learning and Cybernetics, vol. 9, no. 2, pp. 225-241, 2018.

[76] H. Chen-Yi, C. Ke-Ting, and T. Gwo-Hshiung, "FMCDM with fuzzy DEMATEL approach for Customers' Choice behavior model". International Journal of Fuzzy Systems, vol. 9, no. 4, pp. 236-246, 2007.

[77] A. Özdemir and F. Tüysüz, "An integrated fuzzy DEMATEL and fuzzy ANP based balanced scorecard approach: Application in Turkish Higher Education Institutions," Journal of MultipleValued Logic and Soft Computing, vol. 28, no. 2-3, pp. 251-287, 2017.

[78] S. K. Mangla, S. Luthra, S. K. Jakhar, M. Tyagi, and B. E. Narkhede, "Benchmarking the logistics management implementation using delphi and fuzzy DEMATEL," Benchmarking: An International Journal, vol. 25, no. 6, pp. 1795-1828, 2018.

[79] A. Baykasoğlu, V. Kaplanoglu, Z. D. U. Durmuşoglu, and C. Şahin, "Integrating fuzzy DEMATEL and fuzzy hierarchical TOPSIS methods for truck selection," Expert Systems with Applications, vol. 40, no. 3, pp. 899-907, 2013.

[80] S. Opricovic and G. H. Tzeng, "Defuzzification within a multicriteria decision model," International Journal of Uncertainty, Fuzziness and Knowledge-Based Systems, vol. 11, no. 5, pp. 635-652, 2003.

[81] D. Y. Öksüz ve Z. Öztürk, "Türkiye'de savunma sanayinin sanayi sektörünün gelişim sürecindeki rolü," Dünden Bugüne Ekonomi Yazıları II, 1. baskı, A. Orhan, M. R. İnce, ve S. Demir, Ed., Kocaeli, Türkiye: Umuttepe Yayınları, 2019.

[82] D. M. Gligor, M. C. Holcomb, and T. P. Stank, "A multidisciplinary approach to supply chain agility: Conceptualization and scale development," Journal of Business Logistics, vol. 34, no. 2, pp. 94-108, 2013. 
[83] O. Khan and Y. C. Greaves, "Mitigating supply chain risk through 1mproved agility: Lessons from a UK retailer," International Journal of Agile Systems and Management, vol. 3, no. 3-4, pp. 263-281, 2008.

[84] S. Dani and R. Ranganathan, "Agility and supply chain uncertainty: A scenario planning perspective," International Journal of Agile Systems and Management, vol. 3, no. 3-4, pp. 178-191, 2008.

[85] A. Lockamy and K. McCormack, "Examining operational risks in supply chains," Supply Chain Forum: An International Journal, vol. 10, no. 1, pp. 2-14, 2009.

[86] O. Lavastre, A. Gunasekaran, and A. Spalanzani, "Supply chain risk management in French companies," Decision Support Systems, vol. 52, no. 4, pp. 828-838, 2012.

[87] A. Ghadge, S. Dani, R. Ojha and N. Caldwell, "Using risk sharing contracts for supply chain risk mitigation: A buyer-supplier power and dependence perspective," Computers and Industrial Engineering, vol. 103, pp. 262-270, 2017.

[88] D. Pramanik, S.C. Mondal and A. Haldar, "Resilient supplier selection to mitigate uncertainty: Soft-computing approach," Journal of Modelling in Management, 2020, doi: 10.1108/JM2-01-20190027.

[89] H. M. Alzoubi and R. Yanamandra, "Investigating the mediating role of information sharing strategy on agile supply chain," Uncertain Supply Chain Management, vol. 8, no. 2, pp. 273-284, 2020.

[90] T. Wakolbinger and J. M. Cruz, "Supply chain disruption risk management through strategic information acquisition and sharing and risk-sharing contracts," International Journal of Production Research, vol. 49, no. 13, pp. 4063-4084, 2011. 